Review Article

\title{
Study on Creep Characteristics of Expansive Soil in High-Fill Channel of South-to-North Water Transfer Project
}

\author{
Jianhua Guo, ${ }^{1,2}$ Zhangjun Dai $\mathbb{D}^{1},{ }^{1}$ Shichang Li, ${ }^{1,2}$ Nadeem Muhammad, ${ }^{1,2}$ and Hui Gao ${ }^{1,2}$ \\ ${ }^{1}$ State Key Laboratory of Geomechanics and Geotechnical Engineering, Institute of Rock and Soil Mechanics, \\ Chinese Academy of Sciences, Wuhan 430071, China \\ ${ }^{2}$ University of Chinese Academy of Sciences, Beijing 100049, China
}

Correspondence should be addressed to Zhangjun Dai; zjdai@whrsm.ac.cn

Received 19 July 2020; Revised 30 September 2020; Accepted 22 October 2020; Published 12 November 2020

Academic Editor: Guoqing Cai

Copyright (C) 2020 Jianhua Guo et al. This is an open access article distributed under the Creative Commons Attribution License, which permits unrestricted use, distribution, and reproduction in any medium, provided the original work is properly cited.

In the Nanyang section of the midroute of the South-to-North Water Transfer Project, the expansive soil is often used as a filler for high-fill channels. After the channel is stabilized, the expansive soil undergoes creep deformation over time. Studying the creep characteristics of expansive soils in different environments is particularly important for evaluating the safe operation of high-fill channels. In the current study, the creep test of expansive soil under different moisture content and dry density was carried out. It is proposed that the slope of the fitted straight line in the compression curve of the expansive soil can be used to represent the secondary consolidation coefficient of unsaturated expansive soil, and the variation law of the secondary consolidation coefficient under different environmental factors is obtained. The modified Bjerrum calculation method considering the influence of additional load and lateral deformation yields the postexpansion soil settlement curve model to determine the control index range of the project site. Moreover, it is also observed that the secondary consolidation coefficient of unsaturated expansive soil increases with the increase of moisture content and decreases with the increase of dry density. The coefficient of secondary compression of unsaturated expansive soil is linearly related to dry density and moisture content. After the preconsolidation treatment of the expansive soil, when the load level is less than the preload, the secondary consolidation coefficient is smaller, otherwise the secondary consolidation coefficient is larger.

\section{Introduction}

The South-to-North Water Transfer Project is a strategic project to alleviate the severe shortage of water resources in northern China. The main water delivery channel of the midroute of the South-to-North Water Transfer Project is $1472 \mathrm{~km}$ long and passes through a large number of expansive soil areas along the route [1]. The cumulative length of the expansive soil section is about $340 \mathrm{~km}$, accounting for $20 \%$ of the total length (Figure 1). Among them, the middle line project is a gravity flow project. Due to the large terrain fluctuations along the line, to meet the requirements of the channel alignment index and construction technology, it is necessary to take the nearest soil for filling (Figure 2). In the midroute of the South-to-North Water Transfer Project, the length of the canal with a fill height greater than $6 \mathrm{~m}$ is about
$144 \mathrm{~km} \mathrm{[2].} \mathrm{In} \mathrm{the} \mathrm{Nanyang} \mathrm{section} \mathrm{of} \mathrm{the} \mathrm{South-to-North}$ Water Transfer Project, most of the infills are expansive soils. After the completion of the high-fill channel, although the earth pressure tends to be stable, the soil will also produce some creep deformation with the development of time.

Creep refers to the phenomenon that the strain of solid material increases with time under the condition of keeping the stress constant [4]. It is different from plastic deformation. Plastic deformation usually occurs after the stress exceeds the elastic limit, and creep deformation can occur when the stress is less than the elastic limit as long as the stress acts for a long enough time. Creep indirectly affects all processes of soil mechanics, which is an important issue in soil mechanics. The expansive soil in the South-to-North Water Transfer Project is often in an unsaturated state. The creep deformation of unsaturated expansive soil is very slow 


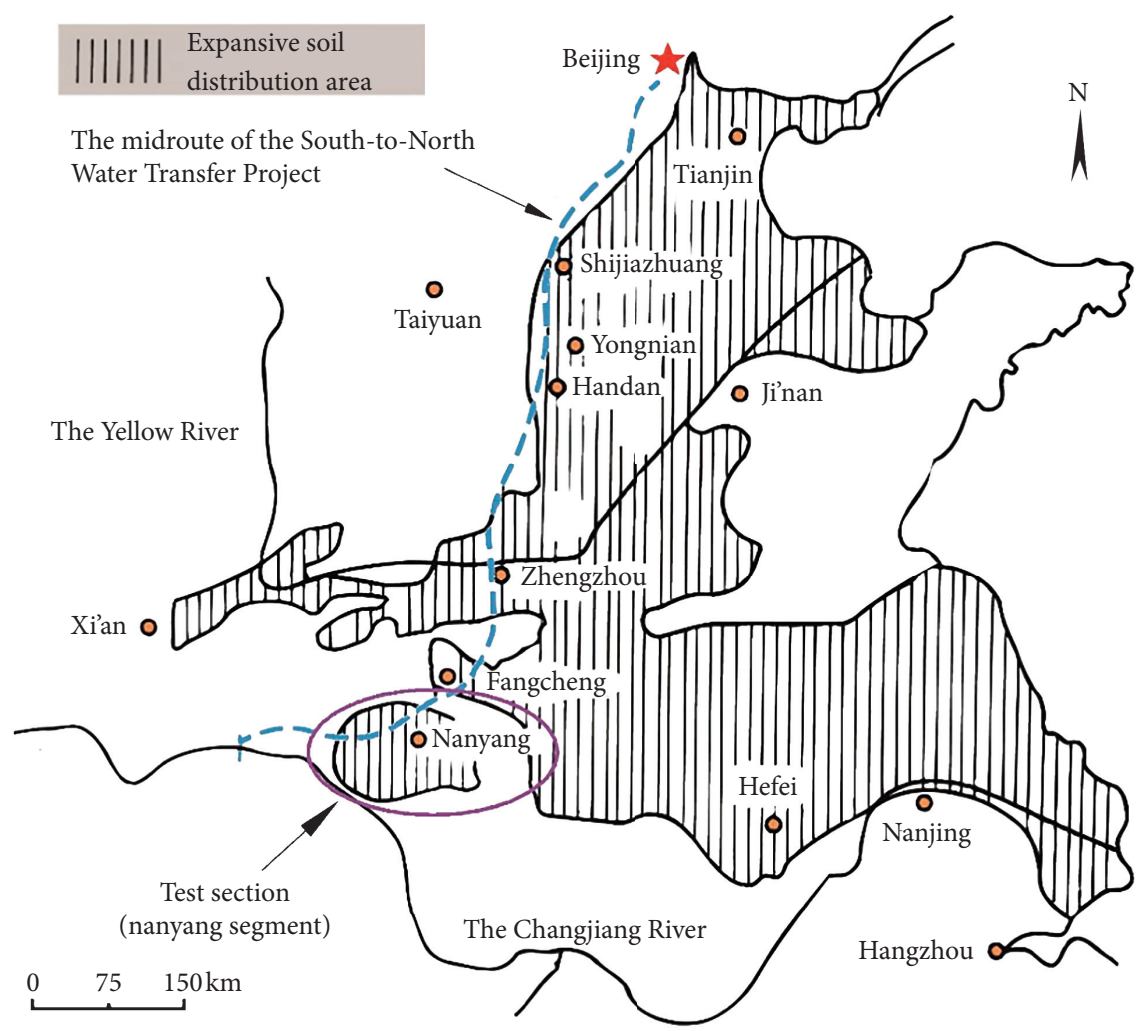

Figure 1: Expansive soil distribution in the midroute of the South-to-North Water Transfer Project of China [3].
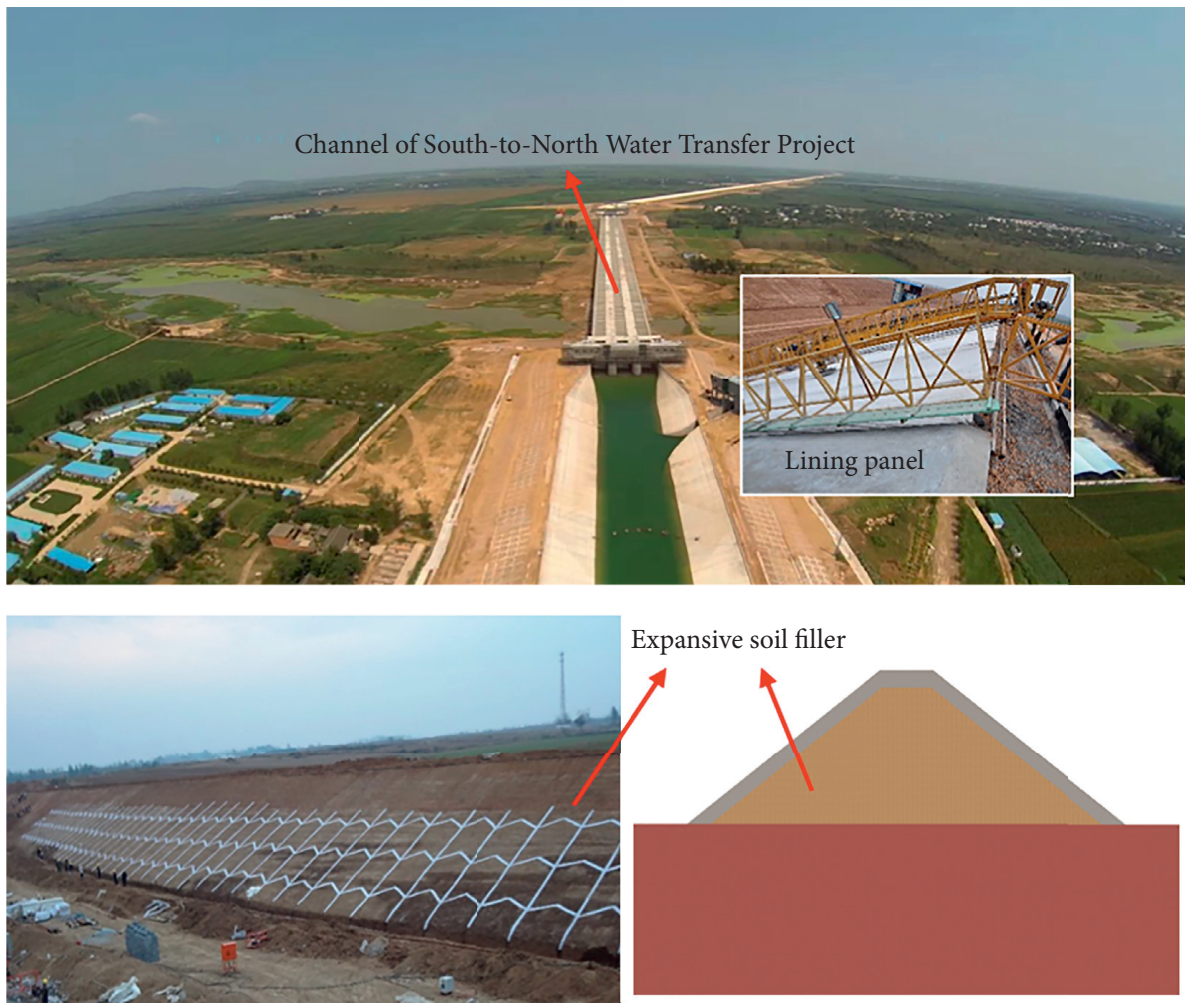

Figure 2: Expansive soil filler of high-fill channel in the Nanyang section of the South-to-North Water Transfer Project. 
and difficult to monitor. With the passage of time and environmental changes, damage such as channel deformation and settlement has occurred, which poses a great threat to the safe operation of the project. Studying the creep characteristics of the expansive fill in different environments is particularly important for evaluating the safe operation of high-fill channels, and it also provides reference for other fill projects.

Researchers have made rapid progress in soil creep tests. Sun et al. [5] studied the creep characteristics of northern red clay. The experimental research was carried out using unsaturated triaxial creep instruments. The study found that the increase in moisture content of red clay also increased the amount of creep. Lai et al. [6] carried out a series of unsaturated triaxial creep tests with soil in the sliding zone of the landslide in the Three Gorges Reservoir area as the research object. The creep test curves under different suction conditions were obtained. It was concluded that as the suction force gradually decreases, the creep deformation and creep rate continue to increase. Chen et al. [7] studied the effects of initial moisture content and fiber content on the creep properties of fiber-reinforced expansive soil through indoor unsaturated triaxial creep tests. The test results showed that creep deformation decreased with the decrease of moisture content, and fiber reinforcement could significantly improve the long-term strength of expansive soil. Li et al. [8] conducted a series of creep tests on Nanning unsaturated expansive soil. Through the analysis of the creep deformation of the expansive soil at each stage, it was obtained that the creep of the expansive soil included the nonlinear creep of viscoelastic deformation and viscoplastic deformation. Li et al. [9] conducted a creep test study on unsaturated foundation soil in Hefei area. The study showed that the creep deformation characteristics of the unsaturated foundation soil under different initial moisture content and different vertical stress were very small. Fruitful results have been achieved in soil creep test research. However, there were relatively few experiments on the creep of unsaturated expansive soils at present because of the high test requirements, long test time, and complex characteristics of expansive soils.

Based on creep tests, a lot of results have been obtained in the study of creep models of soils. Parr [10] established a logarithmic model between cumulative plastic strain and the number of cyclic loadings by performing a cyclic triaxial test on London soft soil. Monismith et al. [11] established an exponential model between cumulative plastic strain and the number of cyclic loadings by conducting experimental studies on expansive soils. Based on Monismith's research, Chai and Miura [12] established an exponential plastic strain empirical formula considering initial shear stress factors. Singh and Mitchell [13] proposed the Singh-Mitchell empirical creep model based on the triaxial creep test, and used three parameters of stress, strain, and time to describe the mechanism of creep deformation. Mesri et al. [14] based on the hyperbolic creep model and the Singh-Mitchell empirical model, further deduced and analyzed the hyperbolic functions of soil stress and strain and time to obtain the Mesri creep model. Zhu and Yin [15] analyzed the experimental data of the relationship between partial stress and time, and used the hyperbolic creep equation to describe the acceleration stage of soil creep. At present, the creep characteristics of soils are often described quantitatively by secondary consolidation coefficients [16-18], and scholars have conducted numerous research on this. Ma et al. [19] studied the long-term compression characteristics of Nanning expansive soil and found that the precompressed modified expansive soil had the lowest secondary compressibility. Yin et al. [20] based on Bjerrum's isochronous e- $\lg p$ curve theory, established a new method for calculating the secondary consolidation coefficient. Based on this calculation method, Zhou and Chen [21] discussed the influence of stress history, loading ratio, and overload preload on the secondary consolidation of the undisturbed soft soil in Nansha of Guangzhou. Ng et al. [22] divided the soil into lowto-moderate compression soil by studying the clay in Shanghai. Lei et al. [23] showed that the secondary compressive coefficient first increased and then decreased with the increase of load, and then tended to stabilize after the study of Tianjin coastal clay. Luo et al. [24] found that the secondary consolidation coefficient of Shantou soft clay first increased with the increase of consolidation pressure, and when increased to a certain degree, it was not affected by the load. Ladd and Preston [25] found that the secondary consolidation coefficient of expansive soil is not affected by time, sample thickness, and graded loading coefficient ratio, and is a reliable parameter. Mesri [26] and Ye et al. [27] considered that the secondary consolidation coefficient is related to consolidation pressure.

It can be observed that the research results of the secondary consolidation coefficient show differences, and the creep characteristics of the soil body are clearly different due to the differences in soil quality and region $[28,29]$. Although the theory of soil creep has made a lot of achievements, there are few studies on the creep characteristics of the soil filling in the channel of the South-to-North Water Diversion. In the South-to-North Water Diversion Project, the channel panel lining has high requirements for canal slope deformation, and creep deformation is an important part of canal slope deformation. Therefore, this paper focuses on the study of the creep characteristics of the expansive soil in Nanyang high-Fill channel. The Nanyang section of the South-to-North Water Diversion Project is located at the junction of North and South China. The special temperate monsoon often causes changes in the external environment, which directly leads to changes in moisture content and dry density. In actual projects, due to geological condition variation, construction control uncertainty, and environmental impact, the differences in moisture content and compactness of the expansive fill often occur. In this paper, the indoor confined compression test under different conditions was carried out on the site-filled unsaturated expansive soil remodeled soil samples taken from the high-fill channel of Henan Nanyang section of the South-to-North Water Transfer Project. By changing the moisture content, dry density, and preload conditions, the creep characteristics of expansive soil under long-term load are studied. The research results provide a corresponding basis for the on-site control indicators of the South-to-North Water Transfer Project. 


\section{Material and Experimental Methodology}

2.1. Characteristics of Test Soil Samples. The test soil sample was taken from the expansive fill of the high-fill channel in the Nanyang section of the midroute of the South-toNorth Water Transfer Project, and the sample was remodeled. Its physical and mechanical properties are shown in Table 1.

The mineral composition of expansive soil was identified by X-ray diffraction. The test used D8 Advance X-ray diffractometer. The results are shown in Table 2.

2.2. Sample Preparation Method. The soil sample was reshaped into a cylindrical unsaturated standard specimen of $\varphi 61.8 \mathrm{~mm} \times h 20 \mathrm{~mm}$, and the specific production steps were as follows:

(1) A crushed air-dried soil sample was passed through a $2 \mathrm{~mm}$ sieve and dried in an oven $\left(T=105-110^{\circ} \mathrm{C}\right.$, $t>8 \mathrm{~h}$ ); then, it is taken out and cooled to room temperature in a desiccator.

(2) The quality of water required to prepare soil samples with moisture content of $15 \%, 18 \%$, and $21 \%$ was calculated. After adding water, put the soil samples into plastic bags.. Subsequently, it was placed in a moisturizing tank for more than $24 \mathrm{~h}$ to make the water in the soil sample mix evenly.

(3) The moisture content of the soil sample was measured by the drying method $\left(T=105-110^{\circ} \mathrm{C}, t>8 \mathrm{~h}\right)$, and the error is within $0.2 \%$.

(4) The required quality of the soil was calculated to prepare the ring knife sample under the design dry density.

(5) The ring knife was stuck back to back firmly, it is placed on a large flat pad, and the weighed soil is poured into it evenly. A metal block of the same size as the ring knife was chosen, and the metal block was pressed into the ring knife with a jack.

2.3. Test Method. The test loading equipment adopted the WG single-lever consolidation instrument (medium pressure) produced by Nanjing Ningxi Soil Instrument Company, as shown in Figure 3, and a total of 15 units were tested at the same time. During the test, the computer automatically displayed and recorded the data throughout the process. To reveal the creep characteristics of expansive soil under different moisture content, dry density, and preload conditions, the following test scheme was adopted.

\subsubsection{The Creep Test Method considering the Influence of Moisture Content (Table 3)}

(1) Loading Method. The loading sequence was 50, 100, 200, 400 , and $800 \mathrm{kPa}$, and the first four loads last for $24 \mathrm{~h}$. Then, the $5^{\text {th }}$ load is applied for the duration until the specimen reached the creep stability standard.

\subsubsection{The Creep Test Method considering the Influence of Dry Density (Table 4)}

(1) Loading Method. The loading sequence was 50, 100, 200, 400 , and $800 \mathrm{kPa}$, and the first four loads last for $24 \mathrm{~h}$. Then, the $5^{\text {th }}$ load is applied for the duration until the specimen reached the creep stability standard.

\subsubsection{The Creep Test Method considering the Influence of Preload (Table 5)}

(1) Loading Method. The preload load application method: the load was applied to the preload load value once for $24 \mathrm{~h}$; then, it is unloaded to 0 for $24 \mathrm{~h}$.

The method of applying the load level: the step-by-step loading method was adopted; except for the last level of load, the remaining loads of each level last for $24 \mathrm{~h}$. The last load duration until the specimen reached the creep stability standard.

\subsection{Creep Characteristics of Expansive Soil}

2.4.1. Secondary Consolidation Coefficient. The porosity of the saturated soil in the secondary compression stage is linearly related to the logarithm of time. According to Mesri's research [26], the secondary consolidation coefficient $C_{\alpha}$ can be obtained from the soil sample's $e$-lg $t$ curve, as shown in the following equation:

$$
C_{\alpha}=\frac{\Delta e}{\lg \left(t / t_{1}\right)},
$$

where $C_{\alpha}$ is the secondary consolidation coefficient (unit: $\left.\mathrm{MPa}^{-1}\right), e$ is the porosity ratio, $t$ is the elapsed time after adding a load, and $t_{1}$ is the main consolidation completion time.

From equation (1), the mathematical meaning of the secondary consolidation coefficient of saturated soil is the slope of the line between $t$ and $t_{1}$ on the $e-\lg t$ curve. When the value of $t$ is the same, the value of $t_{1}$ will affect the value of the secondary consolidation coefficient. Figure 4 shows the relationship between $e$ and $\lg t$ of unsaturated expansive soil under one-time loading conditions and different consolidation pressure of $50 \mathrm{kPa}, 100 \mathrm{kPa}, 200 \mathrm{kPa}, 400 \mathrm{kPa}$, and $800 \mathrm{kPa}$. In the relationship between $e$ and $\lg t$ of unsaturated expansive soil, after a large deformation occurs instantaneously at the moment of loading, the subsequent curve is relatively flat. Compared with the creep curve of saturated expansive soil, the curve of unsaturated expansive soil has no obvious inflection point after instantaneous deformation.

If the calculation theory of secondary consolidation deformation of saturated soil is applied to unsaturated expansive soil, the value of $t_{1}$ will be difficult to determine. If calculated according to the theory of saturated expansive soil, when $t=14400 \mathrm{~min}$ and $t_{1}$ is $1 \mathrm{~min}, 12.25 \mathrm{~min}$, and $100 \mathrm{~min}$, the calculation results of the secondary consolidation coefficient are shown in Table 6.

It can be seen from Table 6 that when the load is $200 \mathrm{kPa}$ and $t=14400$ minutes, the secondary consolidation 
TABLE 1: The physical and mechanical properties of expansive soil samples.

\begin{tabular}{ccccccc}
\hline Liquid limit (\%) & Plastic limit (\%) & Plasticity index & Dry density $\left(\mathrm{g} / \mathrm{cm}^{3}\right)$ & $\begin{array}{c}\text { Optimal moisture } \\
\text { content }(\%)\end{array}$ & $\begin{array}{c}\text { Free expansion } \\
\text { rate }(\%)\end{array}$ & $\begin{array}{c}\text { Specific density } \\
44.4\end{array}$ \\
21.8 & 22.6 & 1.79 & 17 & 60 & 2.62 \\
\hline
\end{tabular}

TABLE 2: Expansive soil mineral composition.

\begin{tabular}{lccccccc}
\hline & \multicolumn{4}{c}{ Mineral composition (\%) } & \multicolumn{2}{c}{ Total clay minerals (\%) } \\
Quartz & Albite & Montmorillonite & Illite & Potash feldspar & Calcite & Oblique chlorite & 19.20 \\
\hline 39.56 & 27.52 & 7.82 & 11.38 & 6.59 & 3.28 & 3.85 & 19.28 \\
\hline
\end{tabular}

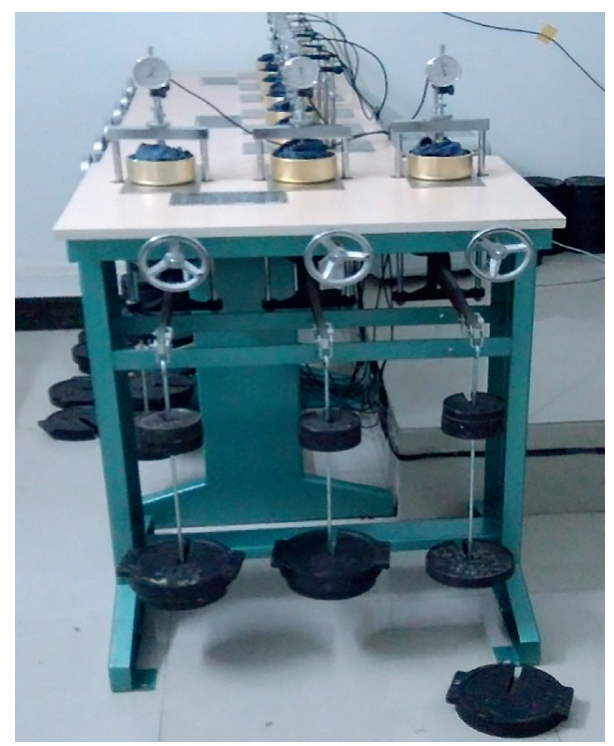

FIGURE 3: WG type single-lever consolidation instrument (medium pressure).

TABLE 3: Creep test schemes with different moisture content.

\begin{tabular}{lccc}
\hline Moisture content $(\%)$ & Dry density $\left(\mathrm{g} / \mathrm{cm}^{3}\right)$ & Preload $(\mathrm{kPa})$ & Loading condition $(\mathrm{kPa})$ \\
\hline 15 & 1.61 & 0 & $50,100,200,400,800$ \\
18 & & & \\
\hline
\end{tabular}

TABle 4: Creep test schemes with different dry densities.

\begin{tabular}{lccc}
\hline Moisture content $(\%)$ & Dry density $\left(\mathrm{g} / \mathrm{cm}^{3}\right)$ & Preload $(\mathrm{kPa})$ & Loading condition $(\mathrm{kPa})$ \\
\hline & 1.52 & 0 & $50,100,200,400,800$ \\
\hline
\end{tabular}

coefficients corresponding to 1 minute, 12.25 minutes, and 100 minutes as $t_{1}$ are $0.001824,0.001280$, and 0.001563 , respectively. The secondary consolidation coefficient corresponding to $1 \mathrm{~min}$ is 1.39 times of the secondary consolidation coefficient corresponding to $12.25 \mathrm{~min}-$ utes. It can be seen that the value of $t_{1}$ has a greater impact on the calculation results of the secondary consolidation coefficient. In order to eliminate this influence and obtain a more reasonable secondary consolidation coefficient of unsaturated soil, a straight line fitting method is selected.

A method for expressing the secondary consolidation coefficient of unsaturated soil trying to fit the test points to a straight line was proposed. According to the creep test of unsaturated soil, the scatter plot under the e-lg $t$ coordinate system was obtained. All the test points are fit after $1 \mathrm{~min}$ into a straight line, and the slope of the straight line is used to represent the secondary consolidation coefficient. During 
TABLE 5: Creep test schemes with different preloads.

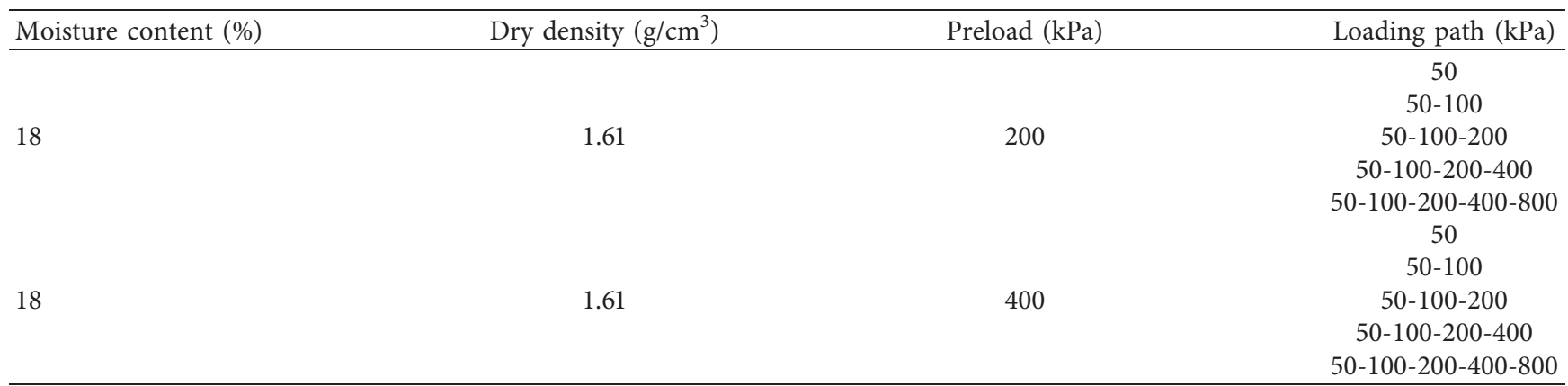

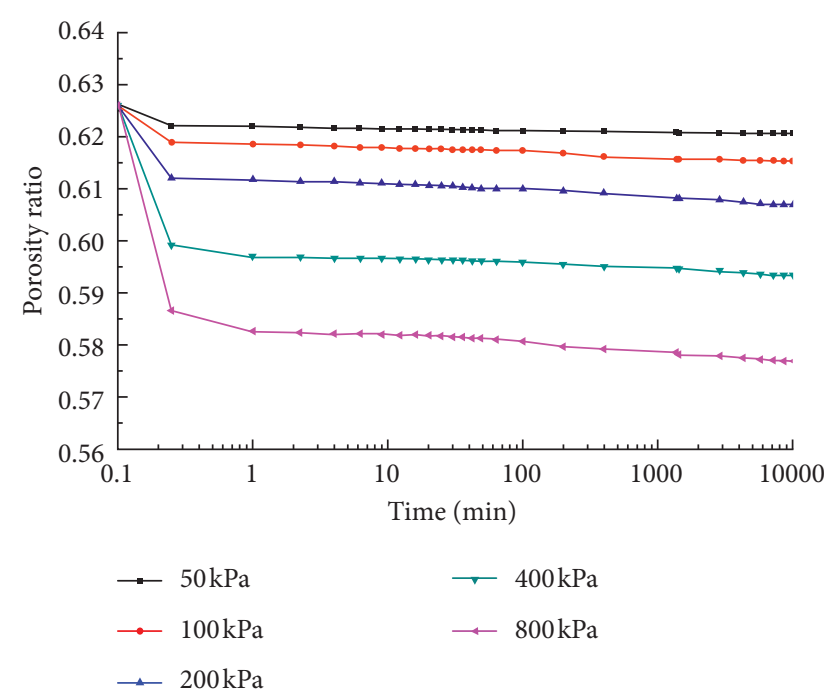

Figure 4: Consolidation test curve of expansive soil under onetime loading conditions.

the fitting process, the square of the correlation coefficient $R^{2} \geq 0.95$ was required. If $R^{2}<0.95$, then it is required to fit all the test points after the next time into a straight line. And so on until $R^{2} \geq 0.95$, the slope of the straight line is used to represent the secondary consolidation coefficient.

The method of fitting the slope of the straight line was used to replace the secondary consolidation coefficient of unsaturated soil to make the secondary consolidation coefficient more accurate.

2.4.2. The Effect of Moisture Content on the Secondary Consolidation Coefficient. Expansive soil is the main soil material filled by the high-fill channel in the Nanyang section of the South-to-North Water Transfer Project, and its special structure and wet swelling, and shrinking properties have special sensitivity to water. Changes in moisture content caused by groundwater level rise, surface evaporation, and atmospheric precipitation infiltration affect the creep deformation of the expansive soil, which in turn may affect the normal use of high-fill channels. Controlling changes in moisture content is particularly important for expansive soils. Through carrying out the creep test of expansive soil under different moisture content conditions, the consolidation creep test curve of expansive soil under different moisture content conditions is shown in Figure 5. The consolidation creep curve of expansive soil under different load levels is shown in Figure 6. The secondary consolidation coefficient of expansive soil under different moisture content conditions is shown in Table 7. Based on the test results, the influence law of moisture content on the consolidation creep characteristics of expansive soil is analyzed.

It can be seen from Figures 5 and 6 that when the moisture content is low and the load level is small, the creep deformation of unsaturated expansive soil is small, and it quickly reaches a stable state. As the moisture content increases and the load level increases, the creep deformation becomes more significant. When the moisture content is low, most of the water contained in the expansive soil is bound water, and only a small amount of free water. Under the effect of a small load level, the loading instantaneously produces large instantaneous deformation due to the rearrangement of the soil particles and the displacement of the soil skeleton, but this process lasts for a short time, and the pore water in the soil has not been discharged. After the instantaneous deformation is completed, due to the small moisture content of the sample, the lubricating effect of the water on the soil is also weak, and the bonding force between the soil skeletons is large. At this time, the structure of the soil is relatively stable under a small load level, and the deformation of the soil skeleton is small. Macroscopically, the vertical deformation of the expansive soil is small, and it quickly reaches a stable state. As the moisture content increases, the lubricating effect of water on the soil body is strengthened, and the bonding force between the soil skeletons is weakened. At this stage, under the action of a larger load level, the structure of the soil is destroyed, and the deformation of the soil skeleton is larger. Macroscopically, it shows that with the increase of the moisture content, the creep deformation of expansive soil is more significant.

It can be observed from Table 7 that changes in moisture content will change the creep rate of the sample. Under the same load level, as the moisture content increases, the creep rate of the sample gradually accelerates, and the secondary consolidation coefficient gradually increases. At a load level of $400 \mathrm{kPa}$, the secondary consolidation coefficient of the soil sample with a moisture content of $15 \%$ is 0.002084 , while the secondary consolidation coefficient of a soil sample with a 
TABLE 6: Calculation table of secondary consolidation coefficient according to saturated expansive soil theory.

\begin{tabular}{lccc}
\hline Consolidation pressure $(\mathrm{kPa})$ & & Secondary consolidation coefficient $\left(\mathrm{MPa}^{-1}\right)$ \\
$t_{1}=1$ minute & 0.000869 & 0.001027 & $t_{1}=100$ minutes \\
\hline 50 & 0.001384 & 0.001178 & 0.001127 \\
100 & 0.001824 & 0.001280 & 0.001424 \\
200 & 0.001966 & 0.001648 & 0.001563 \\
400 & 0.002527 & 0.001898 & 0.001928 \\
800 & & 0.002133 \\
\hline
\end{tabular}

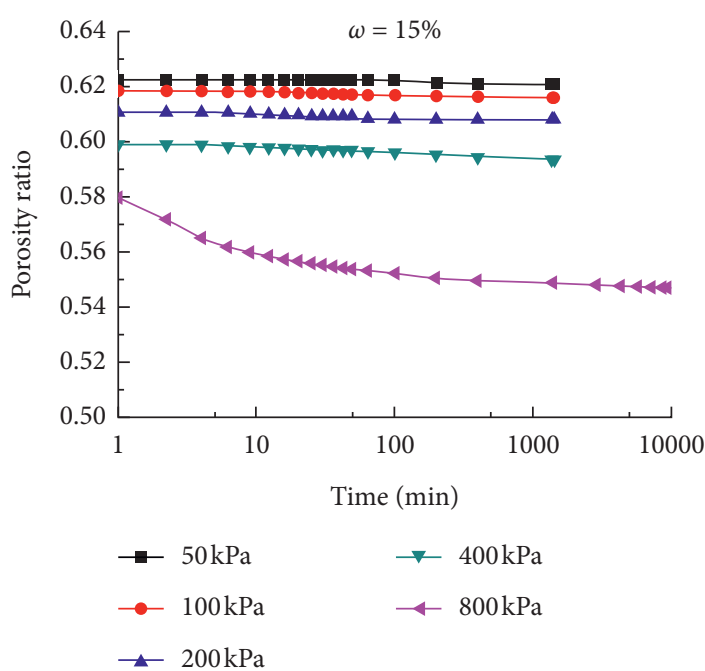

(a)

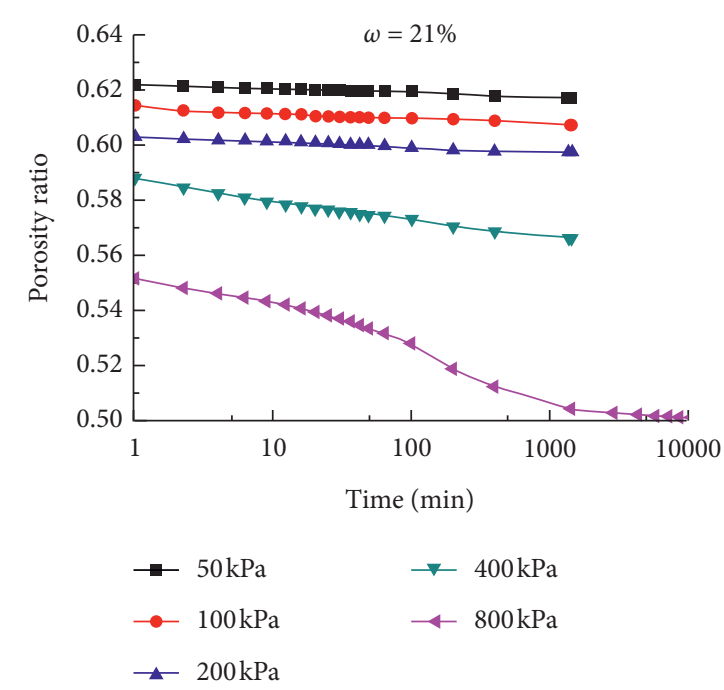

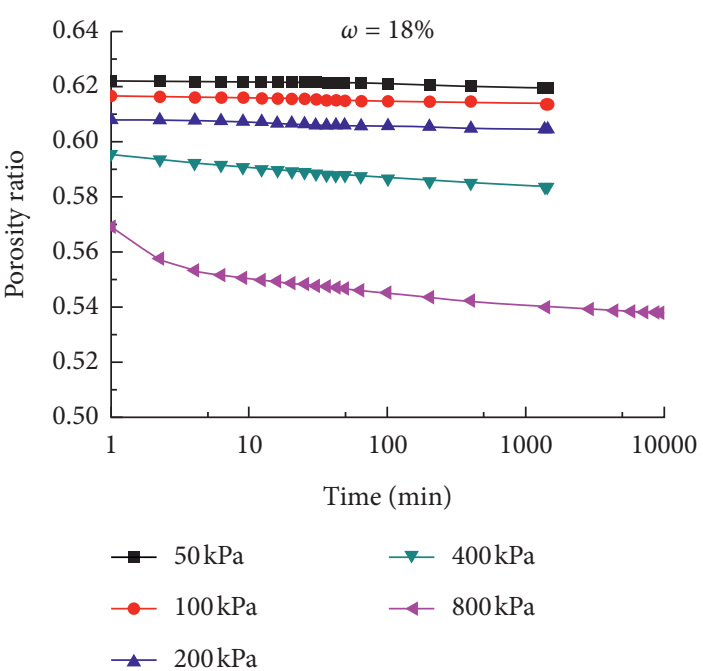

(b)

(c)

Figure 5: Consolidation test curve of expansive soil under different moisture content.

moisture content of $21 \%$ is 0.006022 , which is 2.9 times that of the former. In terms of deformation mechanism, soil has three structural forms: single grain structure, honeycomb structure, and flocculent structure. The stability and strength of the soil structure are mainly related to the strength of the soil particles themselves, the strength of the contact support between the particles, and the chemical bonding strength. The stronger the three, the stronger the soil structure, the higher the strength, and the better the stability. These three strengths are directly related to water. Among them, the strength most affected by water is the strength of chemical bonding between grains. Once dissolved in water, this strength will be significantly weakened, or even zero. The weakening of the intergranular cementation will cause the weakening of the intergranular supporting effect. At this time, the displacement of the soil between the grains is very 

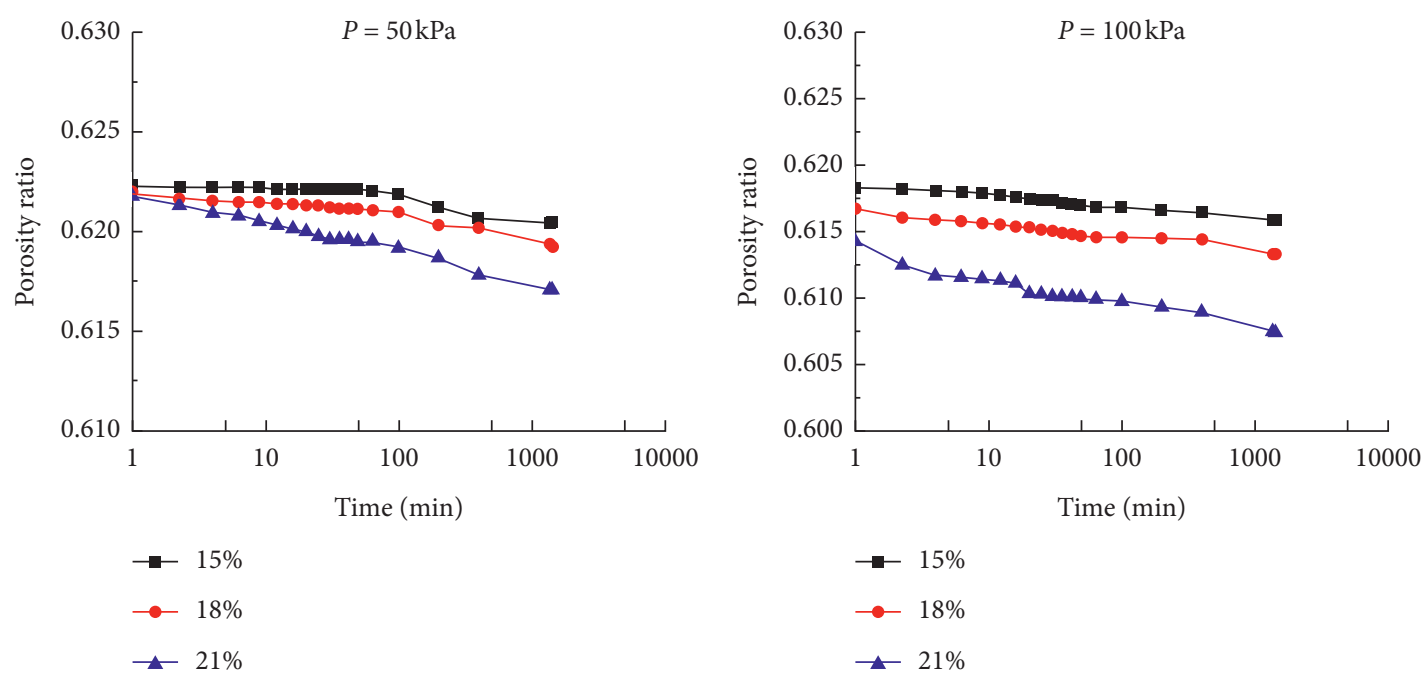

(a)
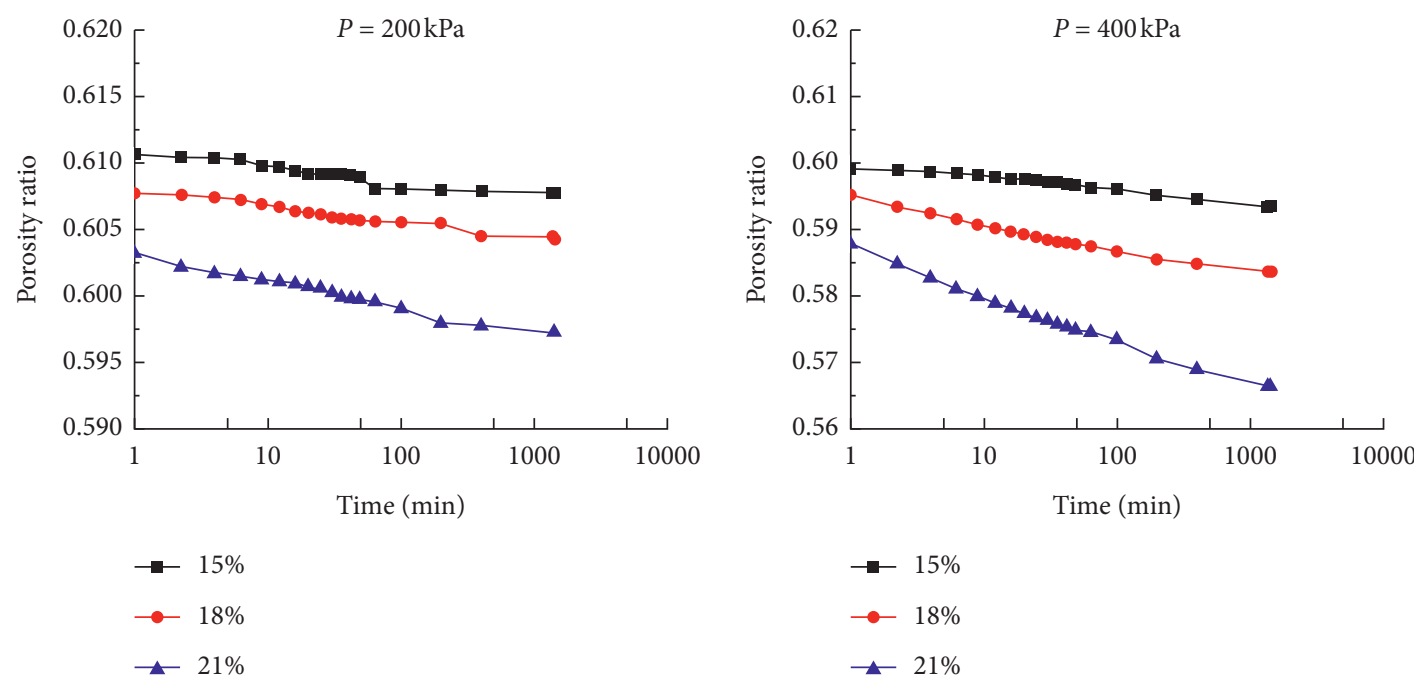

(c)

(d)

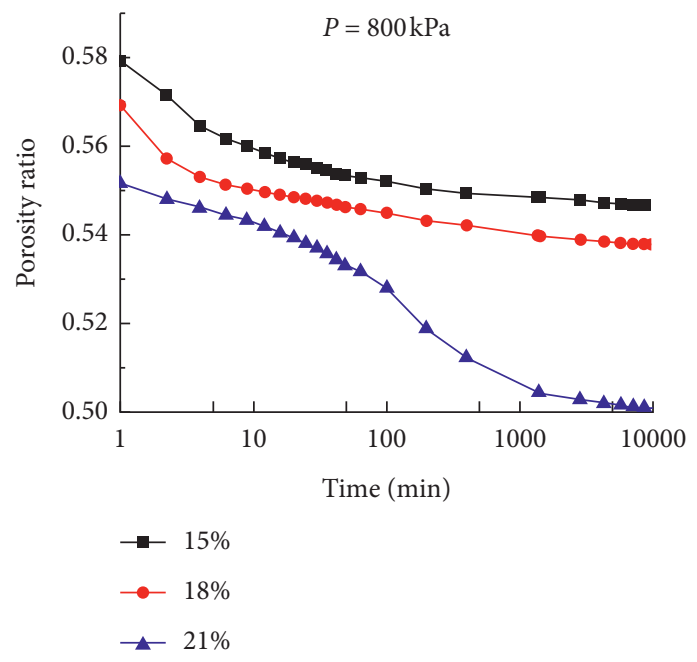

(e)

Figure 6: Consolidation test curves of expansive soil under different consolidation pressure $(P)$. 
TABle 7: Secondary consolidation coefficient table of expansive soil under different moisture content conditions.

\begin{tabular}{|c|c|c|c|c|c|}
\hline \multirow{2}{*}{ Moisture content (\%) } & \multicolumn{5}{|c|}{ Consolidation pressures } \\
\hline & $50 \mathrm{kPa}$ & $100 \mathrm{kPa}$ & $200 \mathrm{kPa}$ & $400 \mathrm{kPa}$ & $800 \mathrm{kPa}$ \\
\hline 15 & 0.000696 & 0.000719 & 0.000962 & 0.002084 & 0.005913 \\
\hline 18 & 0.001087 & 0.001115 & 0.001123 & 0.003131 & 0.006277 \\
\hline 21 & 0.001698 & 0.001821 & 0.001995 & 0.006022 & 0.009304 \\
\hline
\end{tabular}

easy to occur, which eventually causes the strength and stability of the soil to weaken. In severe cases, the strength decreases rapidly to zero, and the structure is completely destroyed. The greater the moisture content in the soil, the stronger the effect of water, the weaker the bonding and contact support between the soil particles, the weaker the strength of the soil, and the greater the deformation.

The main hydrophilic mineral in Nanyang expansive soil is illite, which has strong water absorption. In the presence of pore water in the soil, on the one hand, the water itself plays a role of lubrication; on the other hand, the combination of water and hydrophilic substances illite, montmorillonite, etc. changes the surface properties of the soil particles. A material similar to a lubricant is formed, thereby reducing the suction force between the particles, destroying the structure of the soil, and promoting the orientation of the soil particles during the creep process. In addition, the presence of water will change the physical properties of the expansive soil. With the increase of moisture content, the expansive soil will undergo a softening effect from the solid state to the plastic state to the liquid state. The cohesive force formed by the muddy components in the expansive soil will also decrease due to the softening effect of water. With the increase of moisture content, the effect of water on lubricating, softening, sludge, and flaking of expansive soil particles increases. In terms of numerical values, as the moisture content increases, the secondary consolidation coefficient gradually increases.

Under the same consolidation pressure, the relationship between different moisture content and the corresponding secondary consolidation coefficient is shown in Figure 7. As the moisture content increases, the secondary consolidation coefficient gradually increases; there is an approximate linear relationship between the secondary consolidation coefficient and the moisture content.

According to Figure 7, the relationship between $C_{\alpha}-\omega$ under different consolidation pressures can be expressed as equation (2), and the regression analysis equation under the influence of moisture content is shown in Table 8. When the loading condition is $800 \mathrm{kN}, R^{2}$ is low when linear fitting is used, so linear interpolation is used, as shown in Figure 7(b):

$$
C_{\alpha}=A \omega+C,
$$

where $C_{\alpha}$ is secondary consolidation coefficient, $\omega$ is moisture content, and $A$ and $C$ are fitting coefficients.

\subsubsection{The Effect of Dry Density on the Secondary Consoli-} dation Coefficient. The consolidation creep test of unsaturated compacted expansive soil under different dry density conditions was carried out, and the consolidation creep test curves of compacted expansive soil under different dry density conditions are obtained, as shown in Figures 8 and 9. The secondary consolidation coefficient of expansive soil under various dry density conditions is shown in Table 9. Based on the obtained test results, the effect of dry density on the consolidation creep characteristics of expansive soil is analyzed.

According to Figures 8 and 9, at different load levels, the consolidation test curves of expansive soil under different dry density conditions are roughly similar, and as the dry density increases, the secondary consolidation coefficient gradually decreases. The wedging effect of the water film in the soil sample separates the soil particles. The smaller the dry density of the sample, that is, the fewer the soil particles, the greater the distance between the particles. Under load, a relatively small number of soil particles need to attract each other through a larger distance under the action of clay suction to finally reach a stable spacing between particles. This process shows a greater degree of contraction in the macroscopic form; that is, the secondary consolidation coefficient increases. For the soil samples with higher dry density, the spacing between the particles is relatively small. Under the same load, the decrease in the spacing between the particles is relatively small, and it becomes a soil sample macroscopically. The degree of shrinkage deformation is relatively small; that is, the secondary consolidation coefficient decreases.

On the other hand, as the dry density increases, the density of the sample also gradually increases, the porosity decreases, and the porosity ratio gradually decreases. During the test, under the same load level, the gas in the sample with a small dry density is easier to be discharged, and the pore water is easier to move between particles than the sample with a larger dry density. The more obvious compression characteristics, that is, the secondary consolidation coefficient is larger.

The relationship between different dry densities and corresponding secondary consolidation coefficients under the same consolidation pressure is shown in Figure 10. As the dry density increases, the secondary consolidation coefficient gradually decreases; there is a good linear relationship between the secondary consolidation coefficient and the dry density.

The relationship between $C_{\alpha}-\rho_{d}$ under different consolidation pressures can be expressed as equation (3), and the regression analysis equation derived from Figure 9 is shown in Table 10:

$$
C_{\alpha}=-B \rho_{d}+D,
$$

where $C_{\alpha}$ is secondary consolidation coefficient, $\rho_{d}$ is dry density, and $B$ and $D$ are fitting coefficients. 


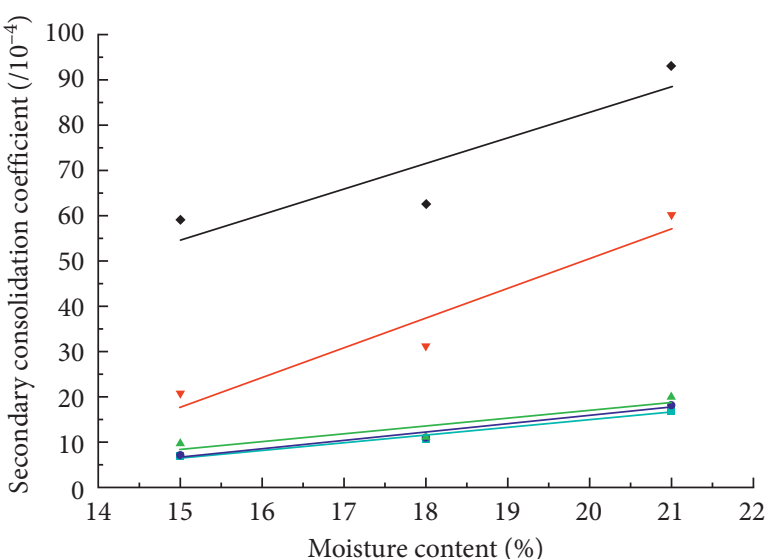

$$
\begin{array}{ll}
=50 \mathrm{kN} & \rightarrow 400 \mathrm{kN} \\
\text { - } 100 \mathrm{kN} & \rightarrow 800 \mathrm{kN} \\
\Delta 200 \mathrm{kN} &
\end{array}
$$

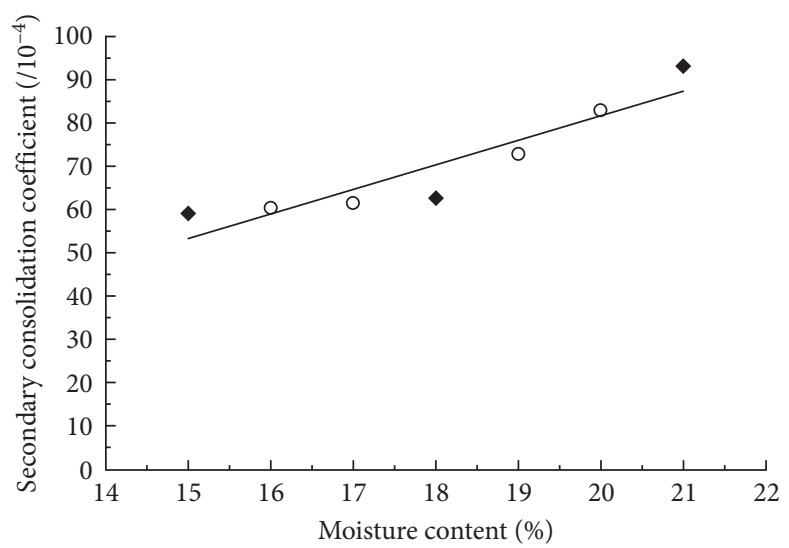

- Data point

○ Interpolation point

(a)

(b)

FIGURE 7: Relationship between moisture content and secondary consolidation coefficient: (a) the result of linear fitting; (b) the result of linear interpolation of $800 \mathrm{kN}$.

TABLE 8: Regression analysis equation under the influence of moisture content.

\begin{tabular}{lccc}
\hline Influencing factor & Consolidation pressure $(\mathrm{kPa})$ & Fitting equation & $R^{2}$ \\
\hline & 50 & $y=0.0167 x-0.0018$ & 0.9842 \\
& 100 & $y=0.0184 x-0.0021$ & 0.9743 \\
Moisture content & 200 & $y=0.0172 x-0.0017$ & 0.8636 \\
& 400 & $y=0.0656 x-0.0081$ & 0.9319 \\
& 800 & $y=0.0565 x-0.0031$ & 0.8569 \\
\hline
\end{tabular}

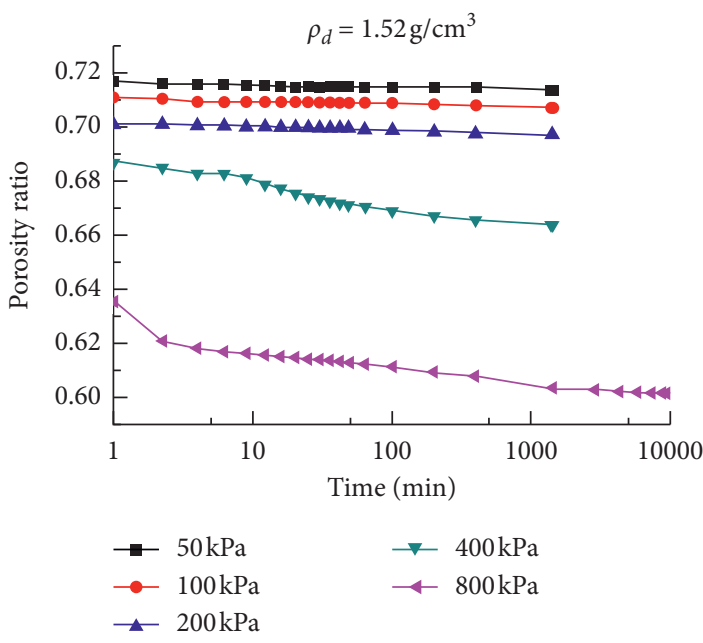

(a)

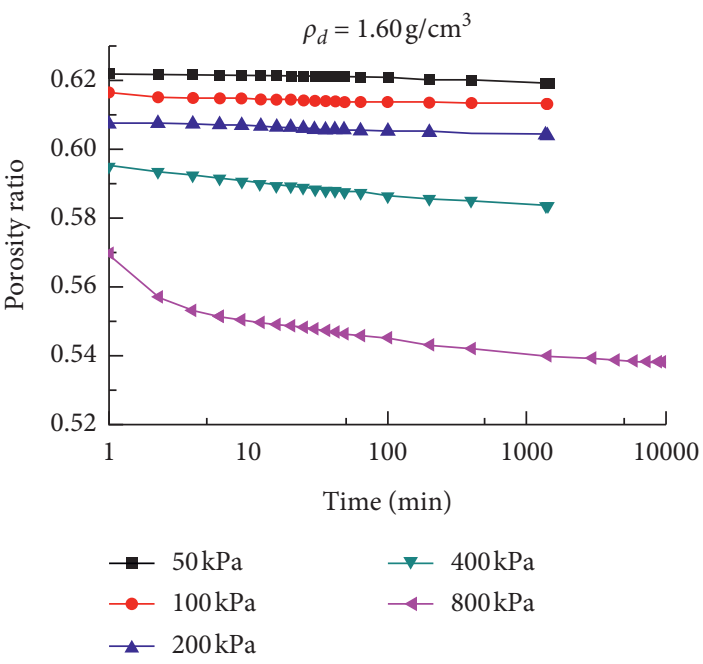

(b)

Figure 8: Continued. 


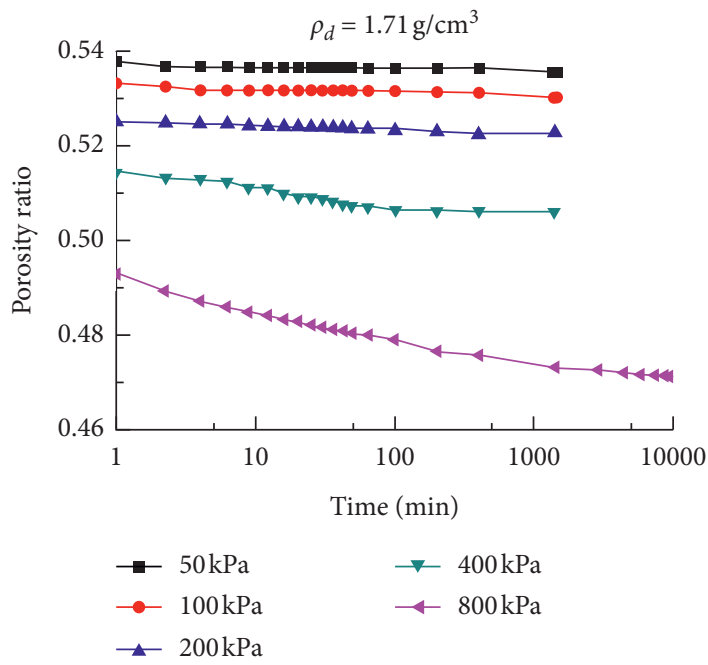

(c)

FIGURE 8: Consolidation test curve of expansive soil under various dry density conditions.
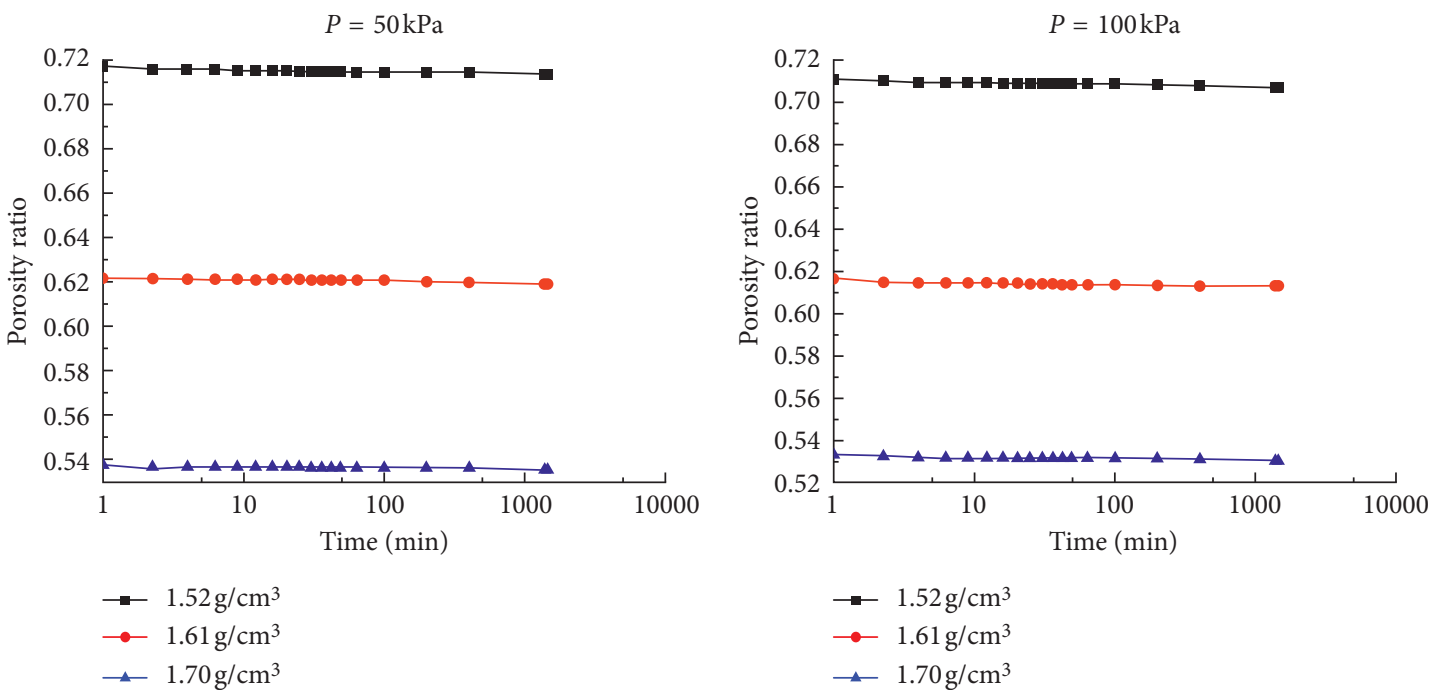

(a)

(b)
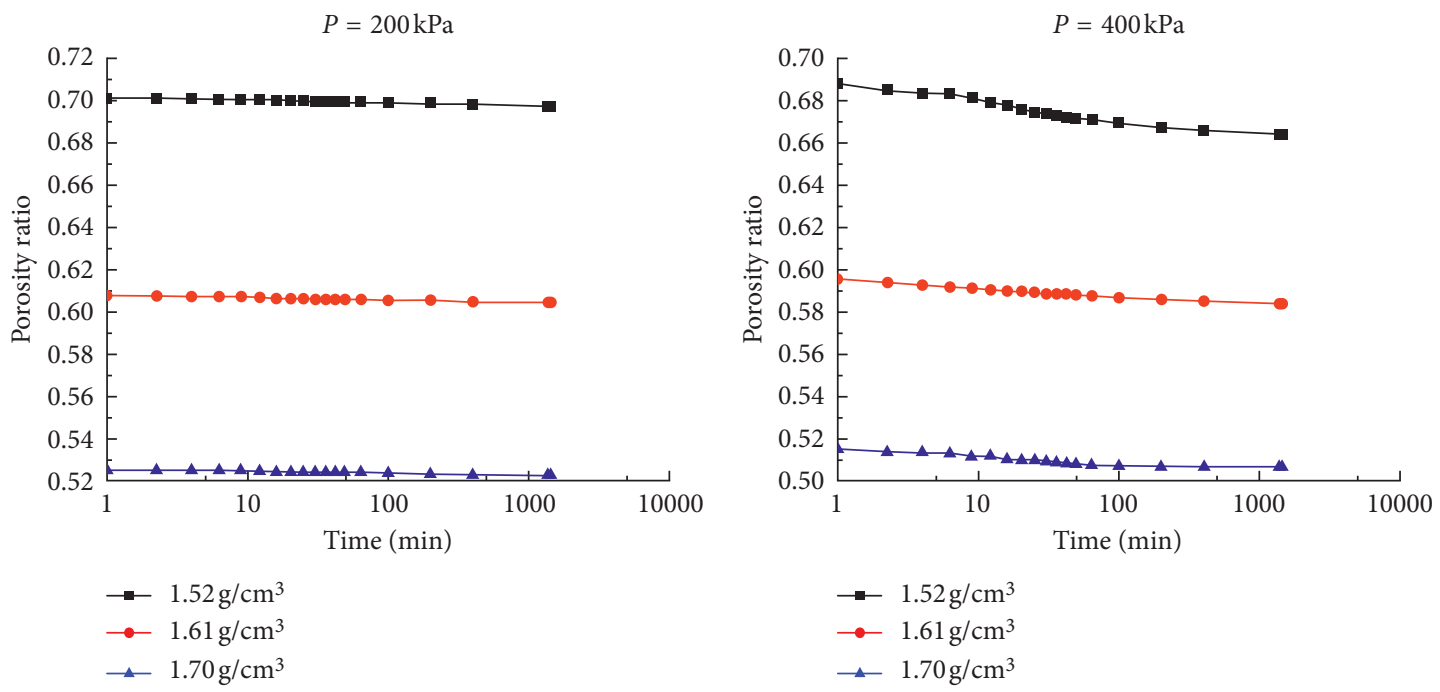

(c)

Figure 9: Continued. 


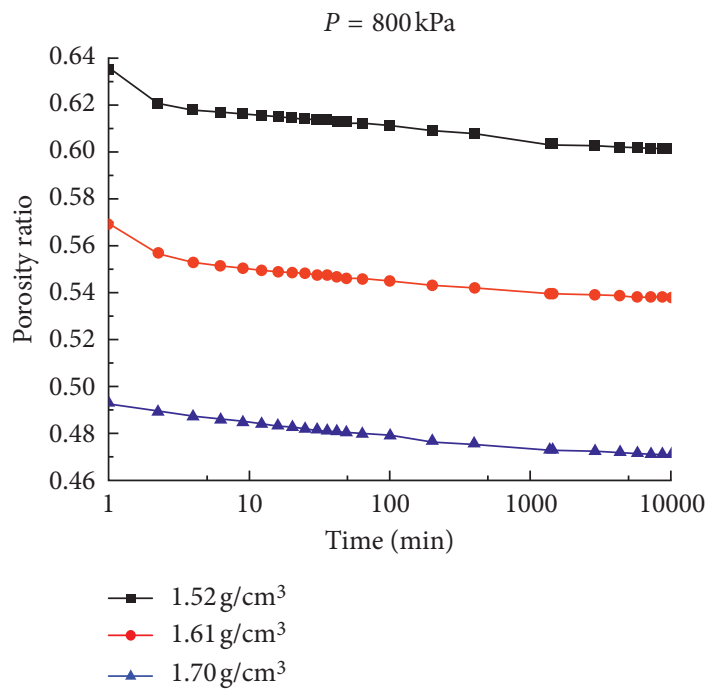

(e)

FIgURE 9: Consolidation test curves of expansive soil under different dry density conditions.

TABle 9: Secondary consolidation coefficient table of expansive soil under different dry density conditions.

\begin{tabular}{|c|c|c|c|c|c|}
\hline \multirow{2}{*}{ Dry density } & \multicolumn{5}{|c|}{ Consolidation pressures } \\
\hline & $50 \mathrm{kPa}$ & $100 \mathrm{kPa}$ & $200 \mathrm{kPa}$ & $400 \mathrm{kPa}$ & $800 \mathrm{kPa}$ \\
\hline $1.52 \mathrm{~g} / \mathrm{cm}^{3}$ & 0.001121 & 0.001245 & 0.001511 & 0.006433 & 0.007663 \\
\hline $1.61 \mathrm{~g} / \mathrm{cm}^{3}$ & 0.001087 & 0.001115 & 0.001123 & 0.003131 & 0.006277 \\
\hline $1.70 \mathrm{~g} / \mathrm{cm}^{3}$ & 0.000697 & 0.000934 & 0.000822 & 0.001848 & 0.005509 \\
\hline
\end{tabular}

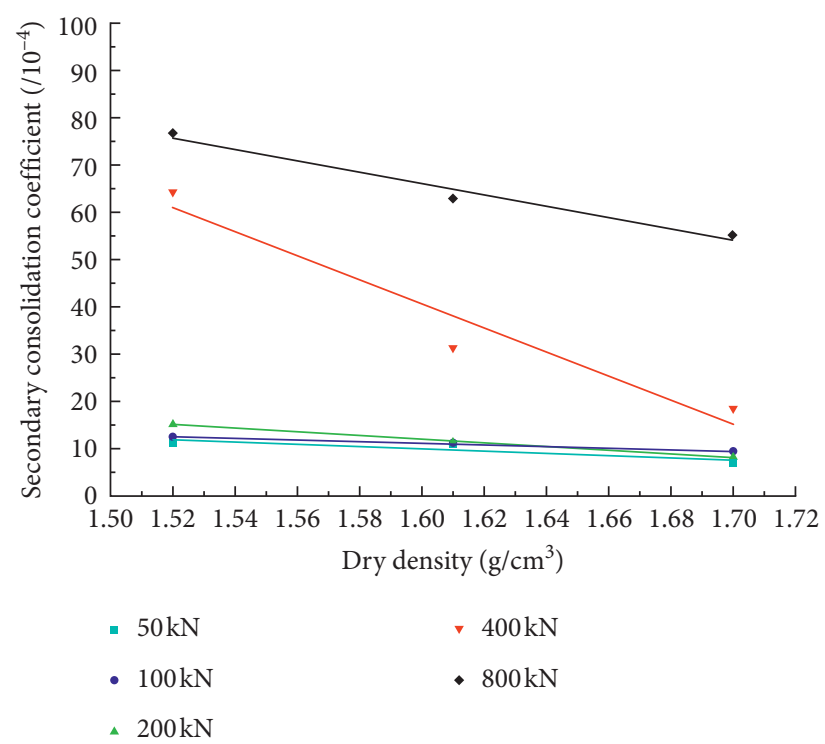

FIgURE 10: The relationship between dry density and secondary consolidation coefficient.

2.4.4. The Effect of Preliminary Consolidation Pressure on the Secondary Consolidation Coefficient. In the South-to-North Water Transfer Project, high-fill fillers are often precompressed, and the strength of the soil increases after the preconsolidation. To study the secondary compression characteristics of unsaturated expansive soil after preconsolidation treatment, compression tests under preload $200 \mathrm{kPa}$ and preload $400 \mathrm{kPa}$ were carried out. The test results are shown in Figures 11 and 12. According to Figures 11 and 12, the secondary consolidation coefficient of 
TABLE 10: Regression analysis equation under the influence of dry density.

\begin{tabular}{lccc}
\hline Influencing factor & Consolidation pressure $(\mathrm{kPa})$ & Fitting equation & $R^{2}$ \\
\hline & 50 & $y=-0.0022 x+0.0045$ & 0.8528 \\
& 100 & $y=-0.0016 x+0.0036$ & 0.9911 \\
Dry density & 200 & $y=-0.0034 x+0.0067$ & 0.9831 \\
& 400 & $y=-0.0225 x+0.0402$ & 0.9089 \\
& 800 & $y=-0.011 x+0.0237$ & 0.9516 \\
\hline
\end{tabular}

compacted expansive soil under different preload conditions is shown in Table 11.

It can be seen from Table 10 that the secondary consolidation coefficient of the soil sample after preconsolidation treatment gradually decreases with the preload relative to the soil sample without preconsolidation treatment. The preconsolidation treatment has a great influence on the secondary consolidation characteristics of expansive soil. After the expansive soil is precompressed, when the final load level is less than the preload, the secondary consolidation coefficient is smaller, and when the final load level is greater than the preload, the secondary consolidation coefficient is larger. It shows that the preconsolidation treatment within a certain range can greatly reduce the secondary consolidation rate of expansive soil. When the load level increases to a certain value, this treatment effect will disappear. This is because after preconsolidation, the soil particles are rearranged and the soil skeleton changes, and the soil structure gradually reaches a stable state that can resist the preconsolidation stress level. And the greater the prestress, the faster this process develops and the greater the degree. When the preload is removed, even if it is reloaded, as long as the applied load is less than the preload, the deformation of the soil skeleton at this time will be "submerged" in the deformation in the preload period, showing a lower secondary consolidation coefficient. Only after the preloading is reached again, the soil skeleton continues to deform and the secondary consolidation coefficient is increased.

2.4.5. The Effect of Expansive Soil Creep Properties on Postconstruction Settlement. The classical model for calculating settlement deformation in engineering is the Bjerrum formula, which is derived under the condition of no lateral deformation. However, in actual engineering, since the length of the high-fill channel is much larger than its width, the channel is in a plane strain state. During the filling process of the channel, with the increase of the channel height and the continuous development of settlement, the stress level and confining pressure of the soil near the slope at the bottom of the channel increased significantly. With the development of the plastic zone, the channel is displaced laterally and causes additional settlement. In a high-fill channel, under the action of a high stress level, the lateral deformation of the soil has a great influence on the settlement of the channel, and the resulting additional settlement cannot be ignored. In addition, for high-fill channels, along with the additional settlement, the lateral displacement of the channel will also reduce the stability of the channel itself.
Therefore, the settlement caused by unidirectional compression must be corrected. The increase in the additional stress caused by the panel and the water storage has different influences on the settlement of each layer of fill due to the influence range and distribution characteristics, and the traditional Bjerrum formula is difficult to consider.

Based on Mesri [26] isochronous $e$-lg $t$ curve, Dai et al. [3] proposed a modified Bjerrum calculation formula considering both the effect of additional load and lateral deformation:

$$
S_{s}=K_{1} K_{2} \sum_{i=1}^{m} \frac{H_{i}}{1+e_{i}} C_{\alpha i} \lg \frac{t_{2}}{t_{1}},
$$

where $S_{s}$ is the amount of creep settlement; $K_{1}$ and $K_{2}$ are the settlement correction coefficients; $H_{i}$ is the height of the $i$-th layer fill; $e_{i}$ is the porosity ratio of the $i$-th layer fill; and $C_{\alpha i}$ is the subcompression coefficient of the $i$-th layer fill.

Based on the results of the consolidation creep test, the right bank channel section of TS95+670-95+770 in the South-to-North Water Transfer Project was used as the work point for calculating the creep deformation of the channel. The test section has a length of $100 \mathrm{~m}$ and a design fill height of $12 \mathrm{~m}$. The structure of the foundation soil layer is a silty clay layer $(5 \mathrm{~m})$, an expansive soil layer $(10.00 \mathrm{~m})$, and a clay rock layer $(31.23 \mathrm{~m})$ from top to bottom. The fill layer is filled with compacted silty clay. The revised Bjerrum formula is used to calculate the postwork creep settlement of the expansive soil layer. The main calculation parameters are shown in Table 12.

In the calculation process, the soil layer needs to be layered. Considering the limited data of the indoor creep test, the soil layer is now divided into two layers, each layer is $5 \mathrm{~m}$ high, that is, $H_{1}=H_{2}=5 \mathrm{~m}$. The secondary consolidation coefficient selected for calculating the creep settlement after the first layer is the value corresponding to the indoor consolidation pressure of $50 \mathrm{kPa}$. The secondary consolidation coefficient used for calculating the creep settlement after the second layer is the value corresponding to the indoor consolidation pressure of $100 \mathrm{kPa}$.

According to the revised Bjerrum calculation formula, the creep deformation results are shown in Figures 13-15.

It can be drawn from Figure 13 that as the moisture content increases, the postwork creep settlement of expansive soil also increases. When the time is $1000 \mathrm{~d}$ and the moisture content $\omega=18 \%$, the postwork creep settlement of the expansive soil layer is $27.50 \mathrm{~mm}$. The postwork creep settlement at the moisture content $\omega=21 \%$ increased rapidly to $43.95 \mathrm{~mm}$, which was 1.6 times that of the former. Therefore, in the actual construction and later use, the 

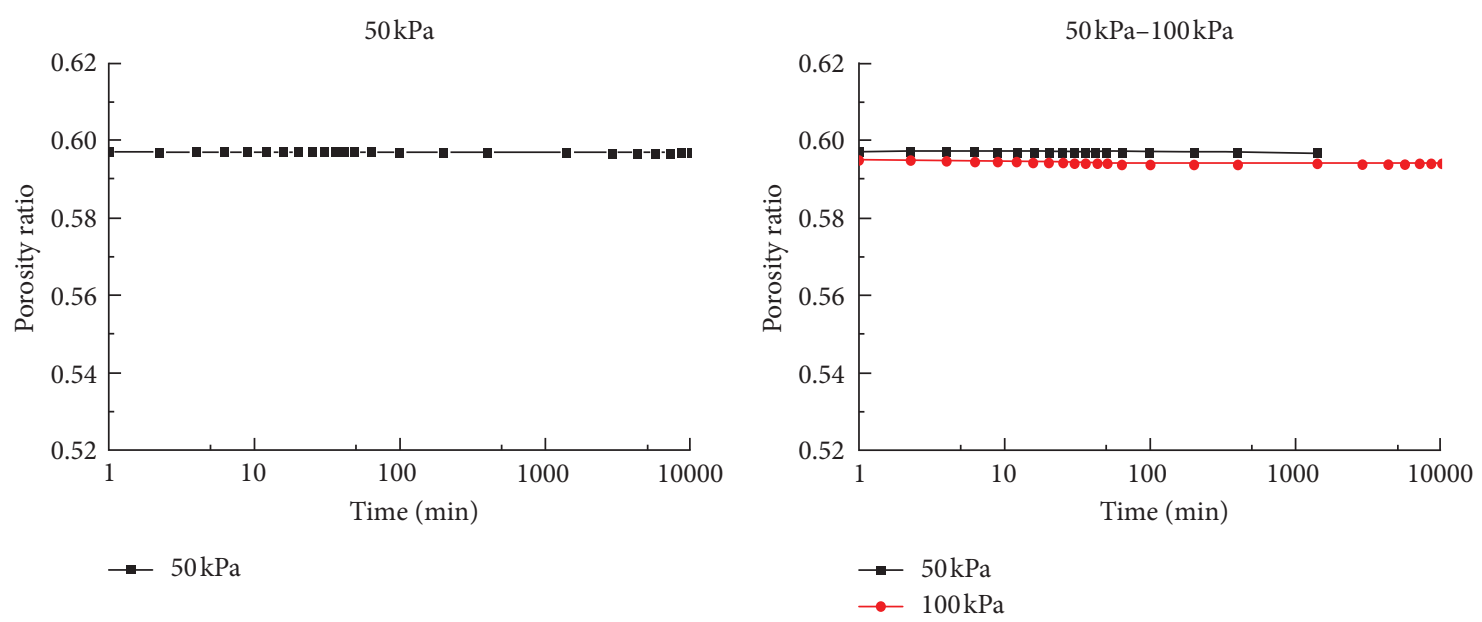

(a)

(b)
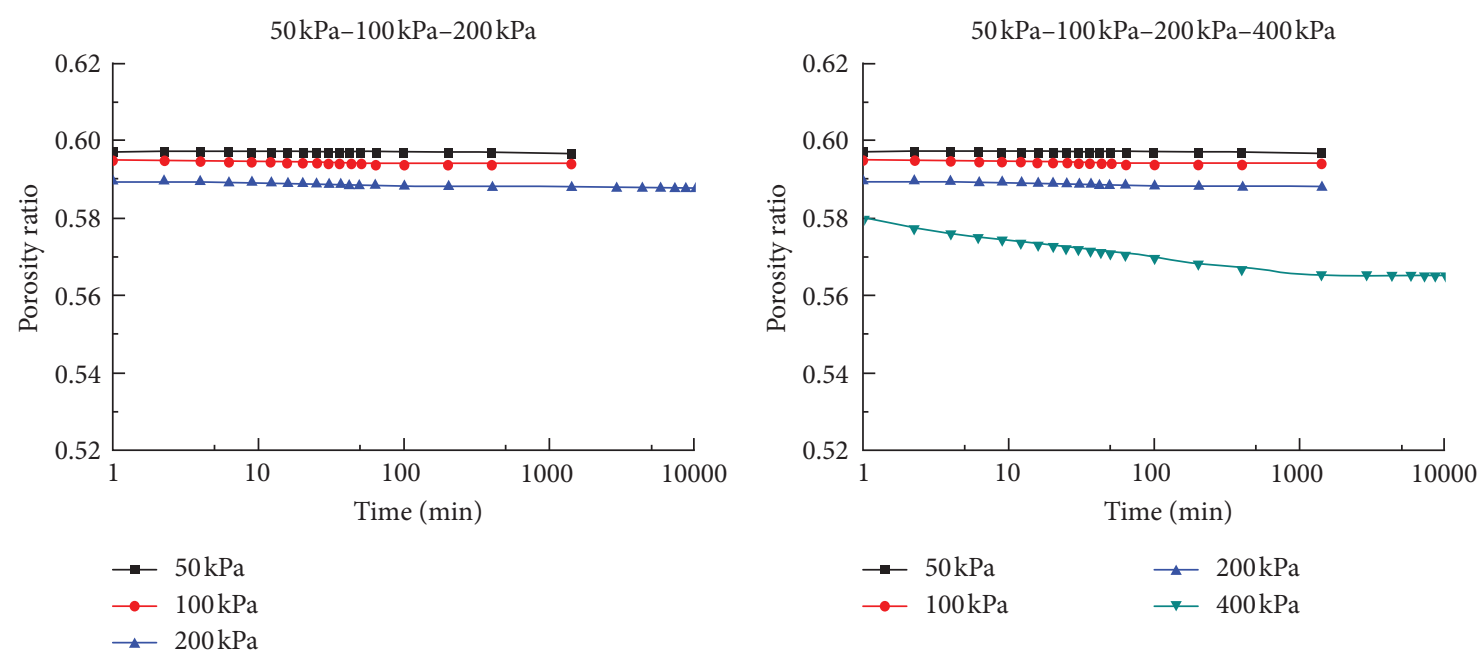

(c)

(d)

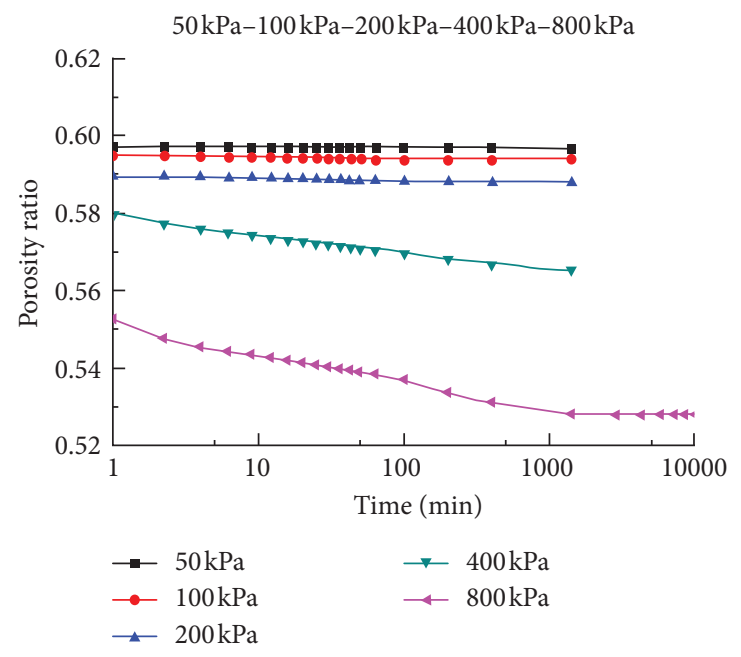

(e)

FIGURE 11: Consolidation test curve of expansive soil under the condition of preload of $200 \mathrm{kPa}$. 


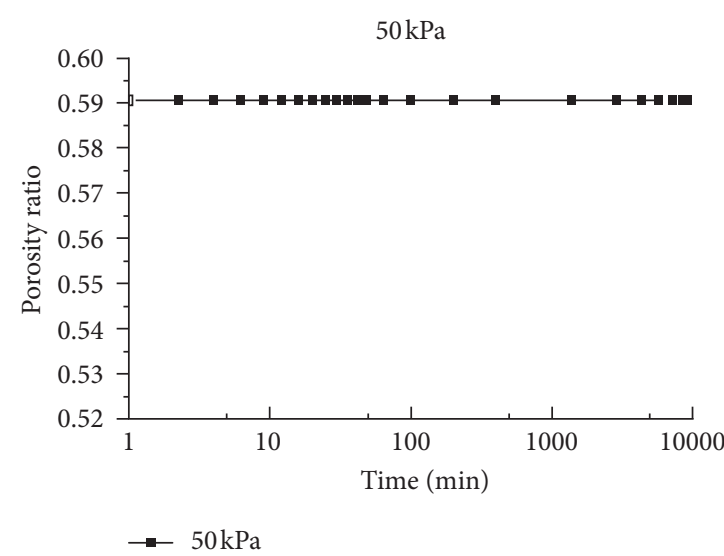

(a)

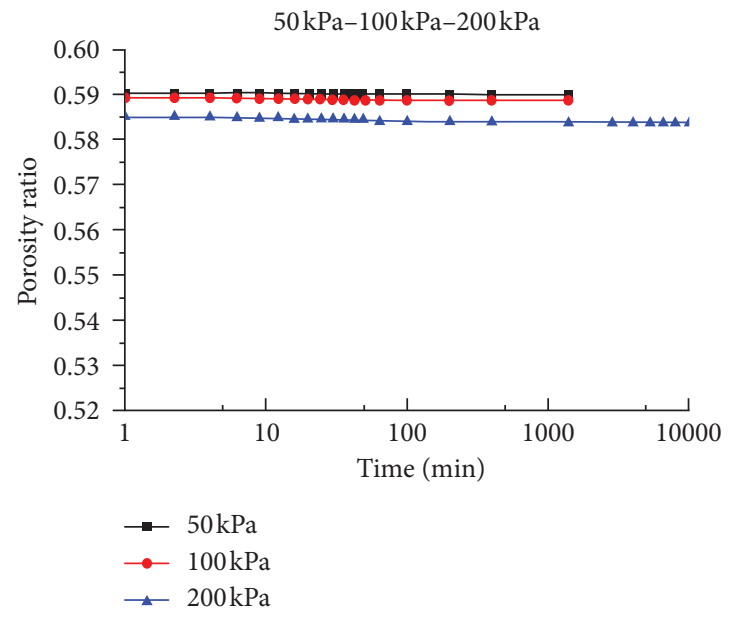

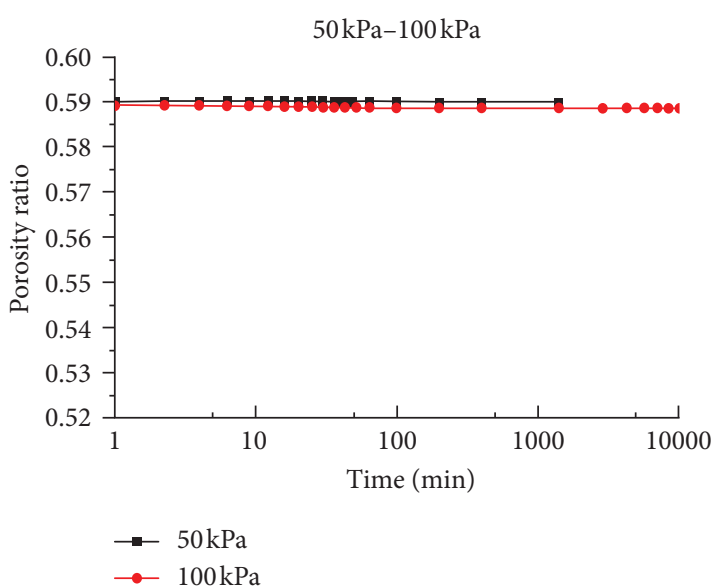

(b)

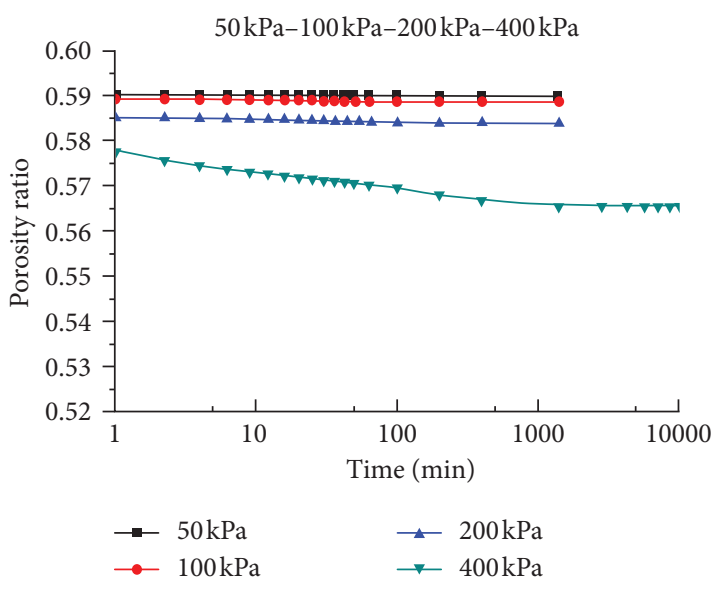

(d)

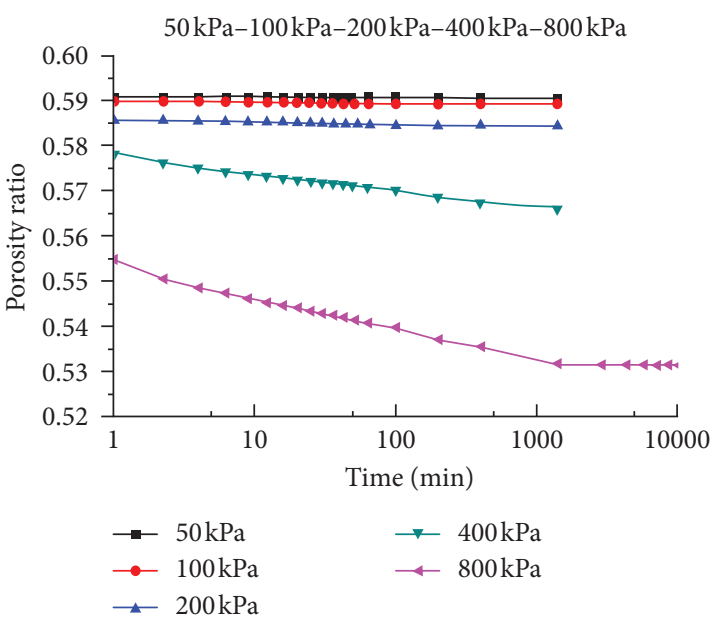

(e)

FIgURE 12: Consolidation test curve of expansive soil under the preload of $400 \mathrm{kPa}$.

moisture content of the expansive soil layer of the high-fill channel should be strictly controlled to prevent damage caused by excessive moisture content. When the moisture content of the weakly expanded fill is greater than $18 \%$, the resulting creep deformation will exceed the postconstruction settlement control standards. Therefore, the moisture content of the expansive soil of the high-fill channel in this section should be strictly controlled, not to exceed $18 \%$.

At the same dry density, the postconstruction settlement gradually increases with time; during the same time, the 
TABLE 11: Table of secondary consolidation coefficients of expansive soil under different preload conditions.

\begin{tabular}{|c|c|c|c|c|c|}
\hline \multirow{2}{*}{ Preload } & \multicolumn{5}{|c|}{ Consolidation pressures } \\
\hline & $50 \mathrm{kPa}$ & $100 \mathrm{kPa}$ & $200 \mathrm{kPa}$ & $400 \mathrm{kPa}$ & $800 \mathrm{kPa}$ \\
\hline 0 & 0.001087 & 0.001115 & 0.001123 & 0.003131 & 0.006277 \\
\hline $200 \mathrm{kPa}$ & 0.000203 & 0.000322 & 0.000491 & 0.001932 & 0.004723 \\
\hline $400 \mathrm{kPa}$ & 0.000127 & 0.000214 & 0.000311 & 0.000979 & 0.003019 \\
\hline
\end{tabular}

TABLE 12: Physical and mechanical properties of layered soil (TS95 + $670-95+770)$.

\begin{tabular}{lccccccc}
\hline Era & Lithology & $\begin{array}{c}\text { Layer thickness } \\
\mathrm{m}\end{array}$ & $\begin{array}{c}\text { Density } \\
\mathrm{kg} / \mathrm{m}^{3}\end{array}$ & $\begin{array}{c}\text { Compression modulus } \\
\mathrm{MPa}\end{array}$ & $\begin{array}{c}\text { Cohesion } \\
\mathrm{kPa}\end{array}$ & $\begin{array}{c}\text { Internal friction angle } \\
{ }^{\circ}\end{array}$ & $\begin{array}{c}\text { Poisson's ratio } \\
\mathrm{Q}^{\mathrm{dl}}\end{array}$ \\
$\mathrm{Q}_{2}{ }^{\mathrm{al}+\mathrm{pl}}$ & Silty clay & 5.00 & 2010.20 & $5 \sim 10$ & 28 & 17 & 0.3 \\
$\mathrm{~N}$ & Expansive soil & 10.00 & 2020.41 & $13 \sim 16$ & 42 & 18 & 0.35 \\
\hline
\end{tabular}

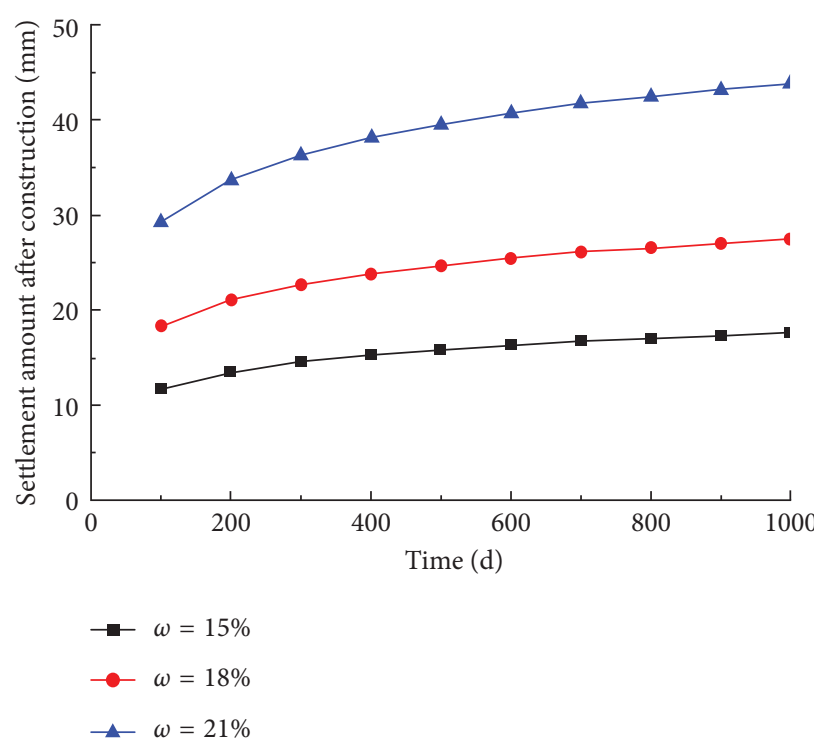

FIGURE 13: The calculation results of creep deformation under different moisture content conditions.

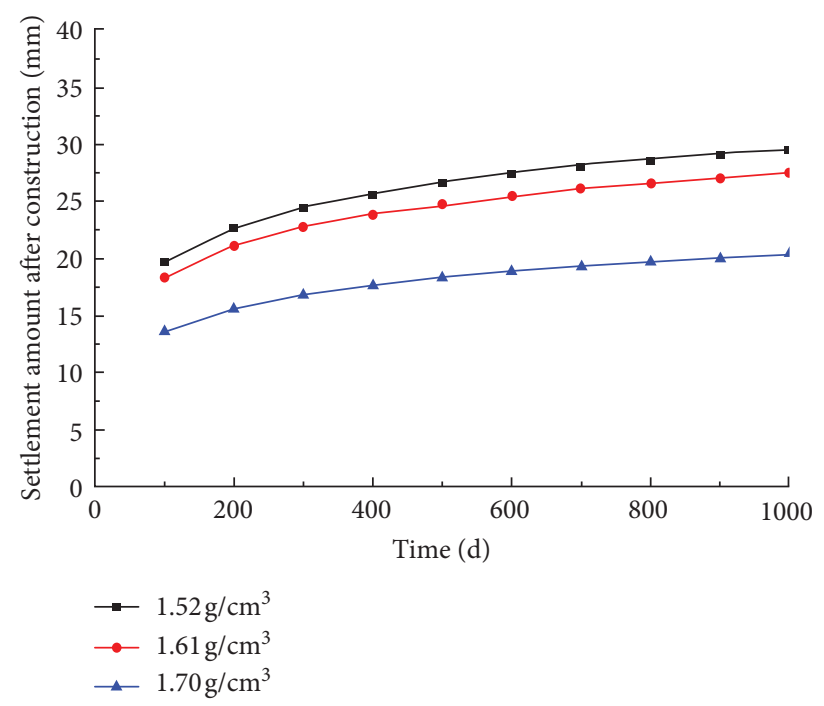

FIGURE 14: The calculation results of creep deformation under different dry density conditions. 


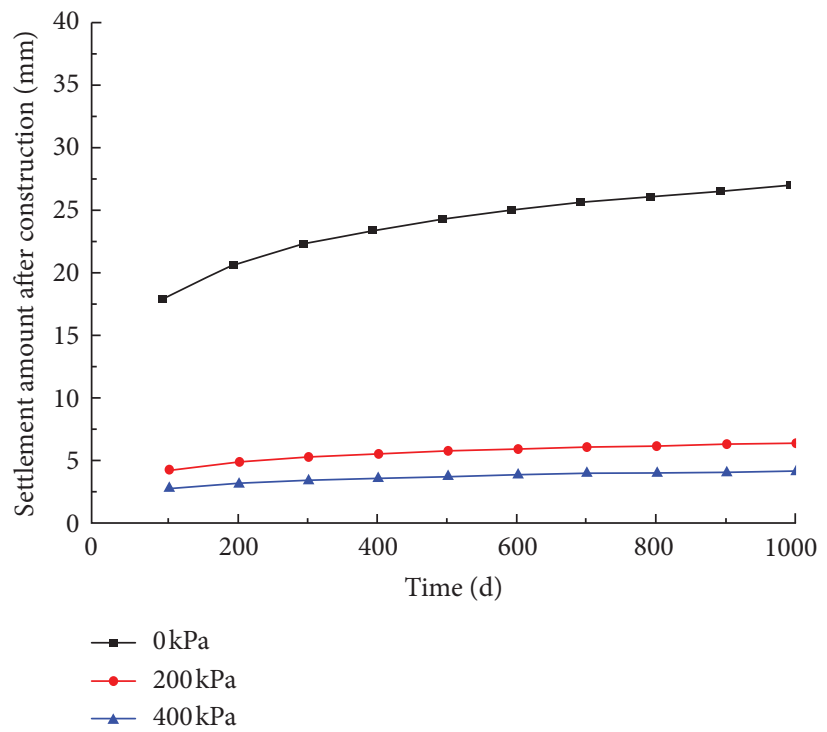

FIGURE 15: The calculation results of creep deformation under different preload conditions.

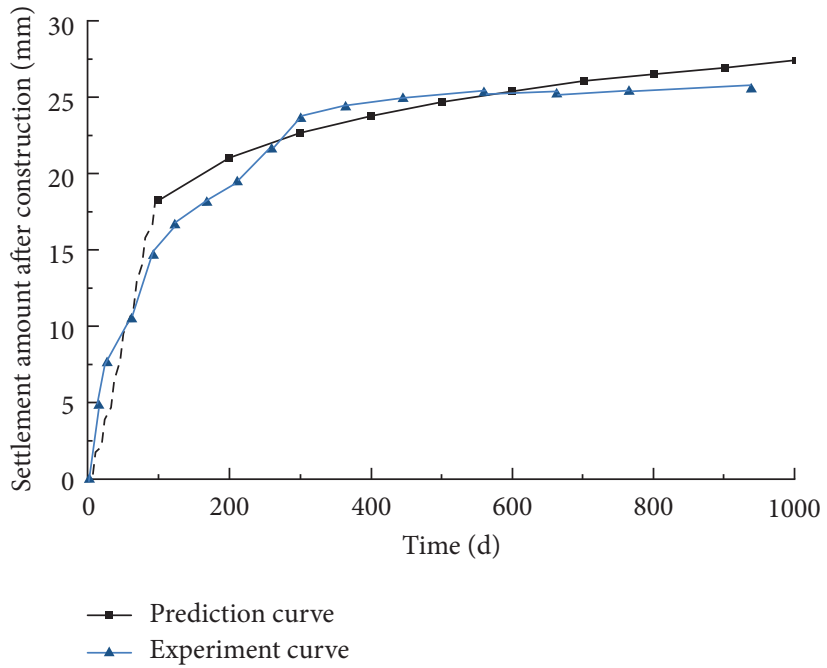

Figure 16: Prediction curve and experiment curve of the test section.

smaller the dry density, the greater the postconstruction settlement of the expansive fill, but the change trend of the postconstruction settlement time history curve is consistent. When the dry density of the expansive fill is less than $1.52 \mathrm{~g} /$ $\mathrm{cm}^{3}$, the resulting creep deformation will exceed the postconstruction settlement control standard. Therefore, the dry density of the expansive soil of the high-fill channel in this section should be strictly controlled to be not less than $1.52 \mathrm{~g} / \mathrm{cm}^{3}$.

It can be noticed from Figure 15 that the preloading treatment has a greater influence on the settlement after construction. Within the design height, under the same load level, the postconstruction settlement after preconsolidation treatment will be significantly smaller than that without preconsolidation, and the greater the preload, the smaller the postconstruction settlement. Conducive to the stability of the channel lining panel. When the time is $1000 \mathrm{~d}$, the postwork creep settlement of the expansive soil layer is $28.90 \mathrm{~mm}$ without preloading. After $200 \mathrm{kPa}$ and $400 \mathrm{kPa}$ prepressure treatment, the postwork creep settlements became $12.89 \mathrm{~mm}$ and $5.54 \mathrm{~mm}$, respectively.

In the Nanyang test section of the South-to-North Water Transfer Project, it could be concluded that the moisture content and dry density were strictly controlled according to the modified Bjerrum calculation formula, wherein the moisture content should not be greater than $18 \%$ and the dry density should be greater than $1.52 \mathrm{~g} / \mathrm{cm}^{3}$. In the construction of the test section, the test conditions with a preload of $0 \mathrm{kPa}$, a dry density of $1.6 \mathrm{~g} / \mathrm{cm}^{3}$, and a moisture content of $18 \%$ were adopted. The actual postconstruction settlement value and predicted settlement value of the test section are shown in Figure 16. Compared with the predicted curve as shown in Figure 16, the predicted curve can better reflect the postconstruction settlement changes. 


\section{Conclusion}

The midroute of the South-to-North Water Transfer Project is an artesian water transfer project. Due to the large topography along the route, a large number of expansive soil high-fill channels appeared in the Nanyang section to meet the requirements of the channel's alignment indicators and construction technology. Engineering accidents caused by creep deformation caused by the long-term action of the soil occur from time to time, and studying the creep characteristics of unsaturated expansive soil has a strong guiding significance for the project. The indoor confined compression test under different conditions was carried out on the site of high-filled channels filled with unsaturated expansive soil taken from the Nanyang section of Henan Province in the middle route project of South-to-North Water Diversion Project, by changing the conditions of moisture content, compaction, and preload to study the creep properties of expansive soil under long-term load. The conclusion is as follows:

(1) The primary consolidation deformation and secondary consolidation deformation of unsaturated expansive soil in the Nanyang section of the Southto-North Water Transfer Project are small, and there is no obvious distinction between them. According to this feature, it is proposed to use the slope of the fitted straight line to represent the secondary consolidation coefficient, instead of using the slope of the connection between the two points to represent the secondary consolidation coefficient.

(2) Because of the special sensitivity of expansive soil to water, the secondary consolidation coefficient of unsaturated expansive soil is greatly affected by the moisture content, and as the moisture content increases, the secondary consolidation coefficient continues to increase. The coefficient of secondary compression of unsaturated expansive soil gradually decreases with the increase of dry density.

(3) The moisture content and dry density of unsaturated expansive soil have a good linear correlation with the secondary consolidation coefficient, in which the moisture content and the secondary consolidation coefficient are positively correlated, and the dry density and the secondary consolidation coefficient are negatively correlated.

(4) The preload will affect the secondary consolidation coefficient of unsaturated expansive soil. After the expansive soil is precompressed, when the final load level is less than the preload, the secondary consolidation coefficient is smaller, and when the final load level is greater than the preload, the secondary consolidation coefficient is larger.

(5) Based on the creep characteristics of unsaturated expansive soil, the postconstruction settlement model of the high-filling expansive soil for the Southto-North Water Transfer Project was established. According to the sedimentation curve, in the right bank channel section of TS95 +670-95+770 in the South-to-North Water Transfer Project, it can be concluded that the moisture content and dry density are strictly controlled, wherein the moisture content should not be greater than $18 \%$ and the dry density should be greater than $1.52 \mathrm{~g} / \mathrm{cm}^{3}$.

\section{Data Availability}

No data were used to support this study.

\section{Conflicts of Interest}

The authors declare that there are no conflicts of interest regarding the publication of this paper.

\section{Acknowledgments}

This research was funded by the National Natural Science Foundation of China, grant no. 41702337.

\section{References}

[1] Z. J. Dai, S. X. Chen, and J. Li, "Physical model test of seepage and deformation characteristics of shallow expansive soil slope," Bulletin of Engineering Geology and the Environment Stage of Publication, vol. 79, pp. 4063-4078, 2020.

[2] Y. Zhang, S. X. Chen, F. Yu, S. D. Xiong, and Z. J. Dai, "Calculation method study of settlement process of high filling channel in south-to-north water diversion project," Chinese Journal of Rock Mechanics and Engineering, vol. 33, no. sup.2, pp. 4367-4373, 2014.

[3] Z. Dai, J. Guo, H. Luo, J. Li, and S. Chen, "Strength characteristics and slope stability analysis of expansive soil with filled fissures," Applied Sciences, vol. 10, no. 13, p. 4616, 2020.

[4] Y. P. Yao and Y. F. Fang, "Negative creep of soils," Canadian Geotechnical Journal, vol. 57, no. 1, pp. 1-16, 2020.

[5] P. P. Sun, M. S. Zhang, T. F. Gu, M. M. Liu, X. Y. Dang, and Y. F. Zhao, "Creeping characteristics of northern red clay under controlled matric suctions," Journal of Engineering Geology, vol. 28, no. 3, pp. 500-509, 2020.

[6] X.-L. Lai, W. M. Ye, and S.-M. Wang, "Experimental study on unsaturated creep characteristics of landslide soils," Chinese Journal of Geotechnical Engineering, vol. 34, no. 2, pp. 286293, 2012.

[7] X. X. Chen, S. S. Du, D. Zhang, B. Li, and T. Y. Ji, "Triaxial creep properties of fiber reinforced expansive soil," Journal of Engineering Geology, vol. 25, no. 1, pp. 80-87, 2017.

[8] Z.-Y. Li, H.-B. Xiao, W.-T. Jin, and W. Yi, "Study of nonlinear rheological model of Nanning expansive soils," Rock and Soil Mechanics, vol. 33, no. 8, pp. 2297-2302, 2012.

[9] X. N. Li, J. Feng, X. X. Wu, and B. L. Zhu, "Experimental study on the creep characteristics of unsaturated foundation soil," Journal of Railway Science and Engineering, vol. 12, no. 5, pp. 1047-1051, 2015.

[10] G. B. Parr, Some aspects of the behavior of london clay under repeated loading, Ph.D. thesis, University of Nottingham, Nottingham, UK, 1972.

[11] C. L. Monismith, N. Ogawa, and C. R. Freeme, "Permanent deformation characteristics of subgrade soils due to repeated loading," Transport Research Record, vol. 537, pp. 1-17, 1975.

[12] J. C. Chai and N. Miura, "Traffic-load-induced permanent deformation of road on soft subsoil," Journal of Geotechnical 
and Geoenvironmental Engineering, vol. 128, no. 11, pp. 907-916, 2002.

[13] A. Singh and J. K. Mitchell, "General stress-strain-time function for soils," Journal of the Soil Mechanics and Foundations Engineering Division, vol. 94, no. SM1, pp. 21-46, 1968.

[14] G. Mesri, E. Febrescordero, D. R. Shields, and A. Castro, "Shear stress-strain-time behaviour of clays," Geotechnique, vol. 31, no. 4, pp. 537-552, 1981.

[15] J. G. Zhu and J. H. Yin, "Drained creep behaviour of soft Hong Kong marine deposits," Géotechnique, vol. 51, no. 5, pp. 471-474, 2001.

[16] V. Favero and L. Laloui, "Impact of $\mathrm{CO}_{2}$ injection on the hydro-mechanical behaviour of a clay-rich caprock," International Journal of Greenhouse Gas Control, vol. 71, pp. 133-141, 2018.

[17] W. Q. Feng, B. Lalit, Z. Y. Yin, and J. H. Yin, "Long-term Nonlinear creep and swelling behavior of Hong Kong marine deposits in oedometer condition," Computers and Geotechnics, vol. 84, pp. 1-15, 2017.

[18] T. M. B. Freitas, D. M. Potts, and L. Zdravkovic, "A time dependent constitutive model for soils with isotach viscosity," Computers and Geotechnics, vol. 38, no. 6, pp. 809-820, 2011.

[19] S. K. Ma, N. F. Zhao, D. Zhou, and B. Y. Pan, "Characteristics study of long-term compressibility of Nanning expansive soil," Rock and Soil Mechanics, vol. 34, no. 8, pp. 2280-2286, 2013.

[20] Z. Z. Yin, H. B. Zhang, J. G. Zhu, and G. W. Li, "Secondary consolidation of soft soils," Chinese Journal of Geotechnical Engineering, vol. 25, no. 5, pp. 521-526, 2003.

[21] Q. J. Zhou and X. P. Chen, "Test study on properties of secondary consolidation of soft soil," Rock and Soil Mechanics, vol. 27, no. 3, pp. 404-408, 2006.

[22] C. W. W. Ng, Q. Li, and G. B. Liu, "Characteristics of onedimensional compressibility of Shanghai clay," Chinese Journal of Geotechnical Engineering, vol. 33, no. 4, pp. 630636, 2011.

[23] H. Y. Lei, X. D. Ding, and Q. Q. LÜ, "Research on secondary consolidation of clay under different squeezing disturbance," Rock and Soil Mechanics, vol. 34, no. 12, pp. 3353-3358, 2013.

[24] Q. Z. Luo, X. Y. Wei, and Q. M. Liu, "Experiment study on secondary consolidation of soft dredger fill," China Civil Engineering Journal, vol. 48, no. sup2, pp. 257-261, 2015.

[25] C. C. Ladd and W. B. Preston, On the Secondary Compression of Saturated Clays, Cambridge: Department of Civil Engineering, MIT, Massachusetts, MA, USA, 1965.

[26] G. Mesri, "Coefficient of secondary compression," Proceedings ASCE, vol. 103, p. 248, 1973.

[27] W. M. Ye, X. L. Lai, Q. Wang, Y. G. Chen, B. Chen, and Y. J. Cui, "An experimental investigation on the secondary compression of unsaturated GMZ01 bentonite," Applied Clay Science, vol. 97-98, pp. 104-109, 2014.

[28] H. Liu, P. F. Li, and Z. Y. Zhang, "Compressional creep test of high embankment settlement," Journal of Southwest Jiaotong University, vol. 39, no. 6, pp. 749-753, 2004.

[29] Q. G. Zeng, C. S. Zhang, and H. B. Xiao, "Test study on secondary consolidation characteristics for Nanning expansive soil," High Engineering, vol. 33, no. 1, pp. 10-13, 2008. 